\title{
The Effect of Inclination on Natural Convective Heat Transfer from a Slender Cuboid
}

\author{
Abdulrahim Kalendar ${ }^{1, *}$, Yousuf Alhendal ${ }^{1}$, Shafqat Hussain ${ }^{2}(1)$ and Patrick Oosthuizen ${ }^{3}$ \\ 1 Department of Mechanical Power and Refrigeration, College of Technological Studies-PAAET, \\ Shuwaikh 23167, Kuwait; ya.alhendal@paaet.edu.kw \\ 2 Department of Mechanical Engineering, The University of Lahore (UOL), 1-Km, Defense Road \\ (Off Raiwind Road), Bhobatian Chowk, Lahore 54000, Pakistan; shafqat.hussain@me.uol.edu.pk \\ 3 Deptartment of Mechanical and Materials Engineering, Queen's University, Kingston, ON K7L 3N6, Canada; \\ patrick.oosthuizen@queensu.ca \\ * Correspondence: ay.kalendar1@paaet.edu.kw
}

Citation: Kalendar, A.; Alhendal, Y.; Hussain, S.; Oosthuizen, P. The Effect of Inclination on Natural Convective Heat Transfer from a Slender Cuboid. Processes 2021, 9, 1668. https:// doi.org/10.3390/pr9091668

Academic Editor: Chengtung Chou

Received: 6 August 2021

Accepted: 9 September 2021

Published: 15 September 2021

Publisher's Note: MDPI stays neutral with regard to jurisdictional claims in published maps and institutional affiliations.

Copyright: (c) 2021 by the authors. Licensee MDPI, Basel, Switzerland. This article is an open access article distributed under the terms and conditions of the Creative Commons Attribution (CC BY) license (https:// creativecommons.org/licenses/by/ $4.0 /)$.

\begin{abstract}
A numerical study was undertaken of the naturally occurring laminar convective heat transfer from a slender cuboid with a relatively narrow cross-section (square) and an exposed top surface. The cuboid was perpendicularly placed on an adiabatic flat base plate and two types of surface boundary conditions were considered. The slender cuboid was inclined relative to the vertical axis at angles ranging from 0 to 180 degrees. The flow was considered symmetrical along the vertical axis of the slender cuboid. The equations governing the system were numerically solved in terms of dimensionless variables using FLUENT software. From the results obtained, mean Nusselt numbers over the slender cuboid were calculated using parameters such as: the Rayleigh number for heat flux, $R a^{*}$; the Rayleigh number, $R a$; the slender cuboid dimensionless width, i.e., the ratio of the width to the height of the heated slender cuboid, $W=w / h$; and the position of the slender cuboid relative to the vertical, $\varphi$. Simulation results were produced for the boundary conditions of constant temperature, constant heat flux, and for $P r=0.7$. The effects of these parameters on the mean Nusselt number for the combined and for the individual surfaces of the slender cuboid are presented and the mean Nusselt numbers are correlated.
\end{abstract}

Keywords: edge effects; constant heat flux; constant temperature; natural convection; laminar; numerical simulations; slender cuboid; inclined

\section{Introduction}

A numerical investigation was undertaken of the natural laminar convective heat transfer from an inclined slender cuboid with a relatively narrow cross-section (square) and an exposed top surface. The slender cuboid positions considered were inclined relative to the vertical axis at angles ranging from 0 (pointing upward) to 180 degrees (pointing downward) from the vertical. The slender cuboid was perpendicularly attached to a plate and two types of surface boundary conditions were considered, constant wall temperature and constant wall heat flux in particular. The cuboid consisted of flat surfaces attached to each other at $90^{\circ}$ angles. The relationship between the natural flows over the heated plates that formed the slender cuboid, shown in Figure 1, is of reasonable engineering practical significance. The interactions between the thermal and fluid flow fields over a cuboid of this kind in various positions are relatively complicated and need to be determined. Natural convective flows over a slender cuboid are distinct because of the buoyancydriven three-dimensional flow involved. The positions and surfaces of the slender cuboid considered are illustrated in Figure 2. The applications that motivated this work meant that it was only necessary to perform the simulations at a Prandtl number of $\mathrm{Pr}=0.7$, which is the value for air. Nowadays, natural heat transfer of the convective type is of great importance in different engineering applications-including cooling and heating 
components, electrical and electronic elements, power devices, solar collectors, and pinfin heat sinks. The processing and operational performance of these elements-which have different shapes, positions, and sizes-has increased markedly. However, they produce more heat and consequently their failure rate has risen, and there is a need for preferably methods of cooling. The inability of electric and electronic components (EECs) to remain cool means that their potential high-speed and efficient performance is in jeopardy, unless heat transfer abilities and thermal design can be improved (see Incropera [1] and Honnor et al. [2]). Several characteristics that affect the rate of heat transfer from EECs have to be taken into account; e.g., the velocity of the coolant, different types of coolant, cooling technique, surface area, and position.

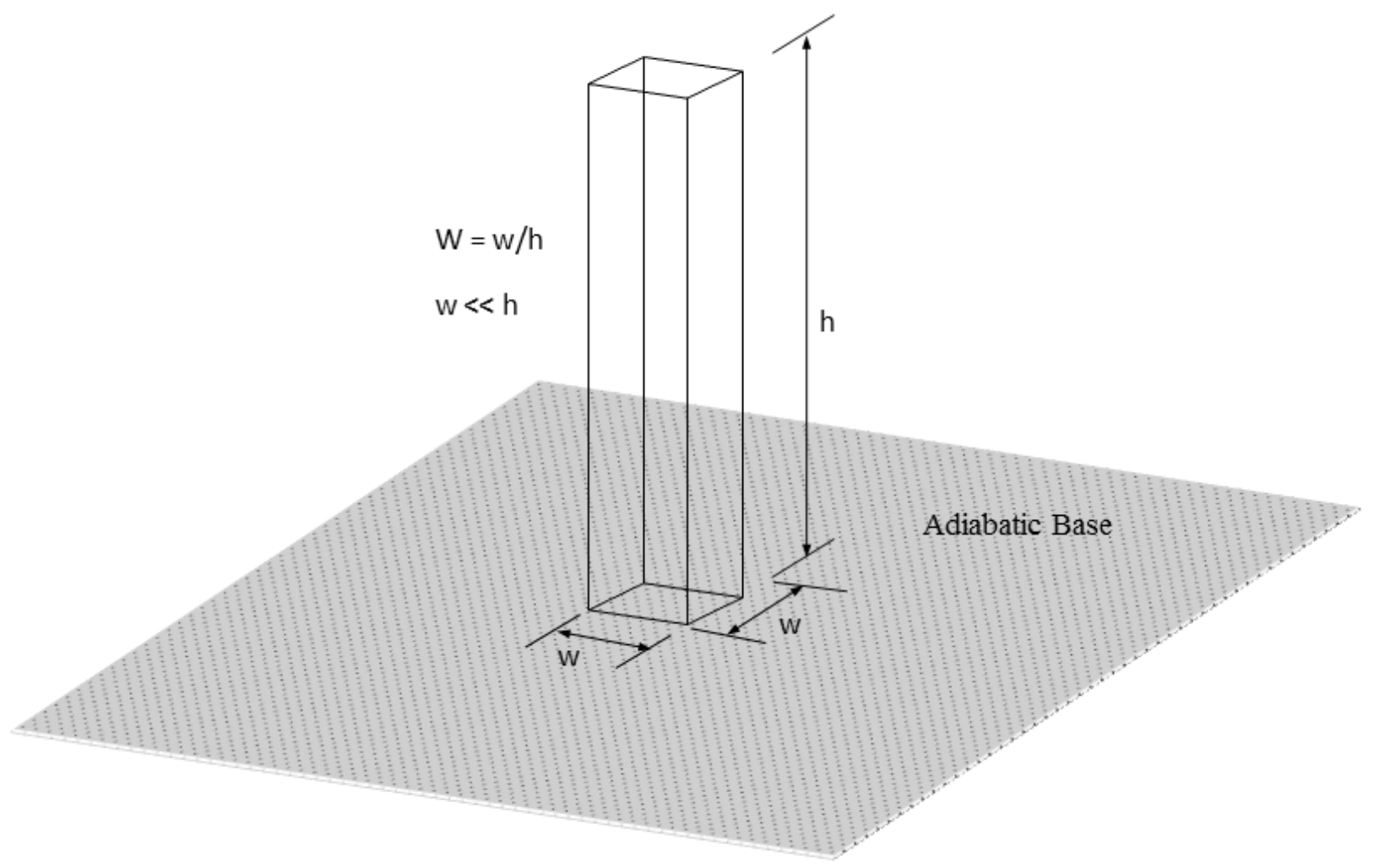

Figure 1. Diagram of the slender cuboid.

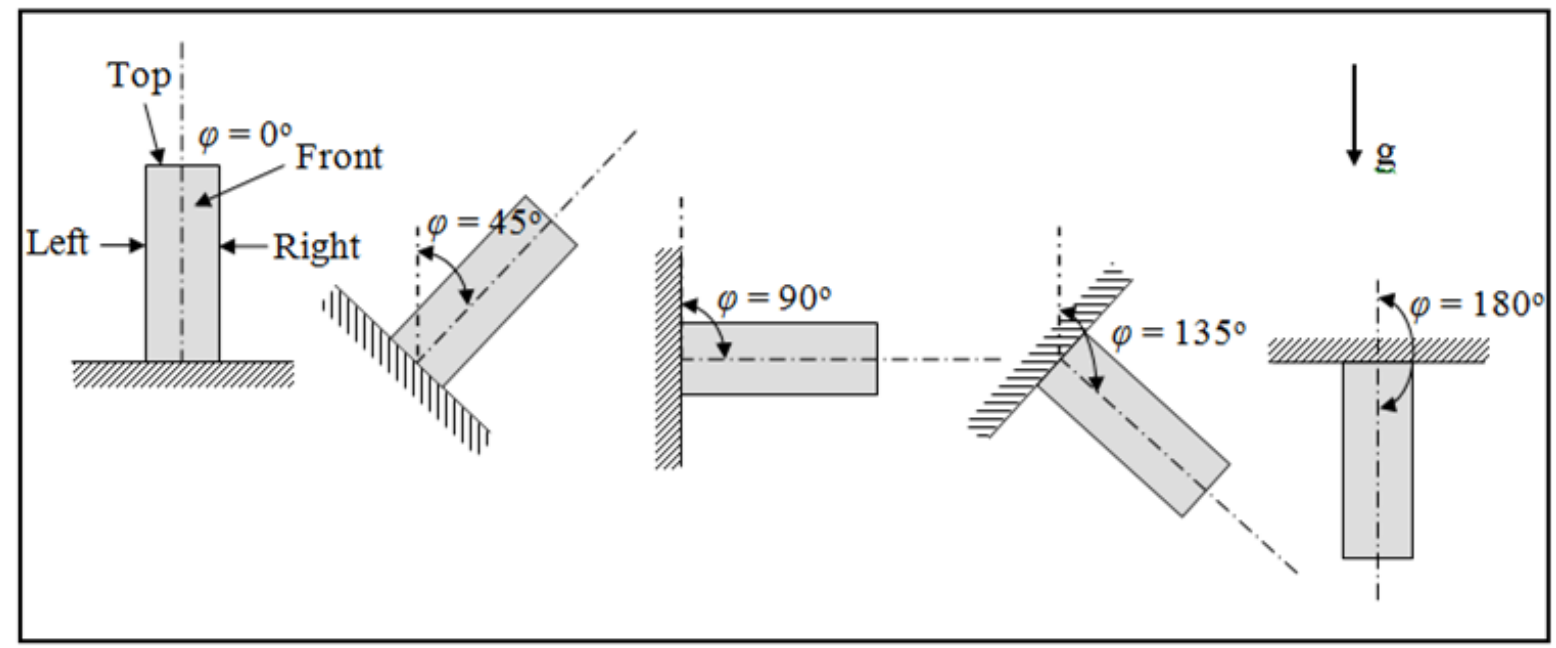

Figure 2. Illustration of the positions and surfaces of the slender cuboid. 
Progress in EEC technologies has enormously increased their speed and processing performance, while at the same time their size and weight have been reduced; however, the features of their flow and heat transfer are different from those of their bigger counterparts. An Air Force survey conducted by Yeh [3] indicates that temperature is the main source of failure for more than $50 \%$ of its electronic elements. Hence, the design, development, and manufacturing of reliable cooling methods requires a clear understanding of enhanced heat transfer, thermal control, and heat removal techniques (see Dave [4]). The best thermal design of EECs cooled down through the process of natural convection is dependent on the precise selection of sizes, geometrical structures, and heat sources. The process of naturally occurring heat transfer of the convective type from cylinders with a circular cross-section and different orientations has been previously investigated, and reported in several heat transfer books, including Incropera et al. [5], Burmeister [6], Oleg and Pevel [7], Cebeci [8], and Rohsenow et al. [9]. However, the majority of investigations reported in these books deal with two-dimensional flow over cylinders. Some researchers have investigated circular cylinders in which the diameter-to-length ratio is small (see refs. Le Fevre and Ede [10], Crane [11], Oosthuizen [12], Oosthuizen and Paul [13], Oosthuizen [14], Oosthuizen and Paul [15], Eslami and Jafarpur [16], Popiel [17], and Popiel et al. [18]). The effects of the shape of the body, orientation, and dimensions on laminar natural convection from isothermal axisymmetric and three-dimensional body shapes—such as circular and square cylinders-were investigated, as in Lee et al. [19], Yovanovich [20], Radziemska and Lewandowski [21], and Hassani [22]. Correlations and analytical solutions were derived to estimate the mean Nusselt number and found a strong agreement with existing analytical and experimental values.

Numerical studies of the characteristic heat transfer and flow of laminar naturally occurring convection around a horizontal isothermally heated square cylinder at different angular orientations between $0^{\circ}$ and $90^{\circ}$ have been carried out by Mahmud et al. [23]. The aforementioned work showed that the maximum rates of heat transfer from a square cylinder occur at an angular orientation of $45^{\circ}$ for a constant Grashof number. Popiel and Wojtkowiak [24] experimentally investigated natural convective heat transfer from isothermal inclined and vertical square cylinders using a lumped capacitance method. It was demonstrated, using empirical equations, that the measured values of the mean Nusselt numbers for the widest square cylinder were higher than the predicted values for a wide flat plate. Furthermore, Al-Arabi and Sarhan [25] studied natural convective heat transfer in turbulent flow regions and in laminar flow around an isothermal square cylinder inclined at angles between $0^{\circ}$ and $90^{\circ}$, where the ends were insulated. They revealed that heat transfer from the square cylinder depends on the angle of inclination and the side-tolength ratio due to the existence of edge effects. Oosthuizen [26,27] studied heat transfer convection from a vertical square cylinder (isothermal) using $w / h$ ratios in the range 0.1 to 1 and Rayleigh numbers in the range $1 \times 10^{4}$ to $1 \times 10^{7}$. It was found that decreasing the values of the Rayleigh number and the $w / h$ ratio resulted in an increase in the mean Nusselt number. A correlation equation was established for the vertical side surfaces and the top of the square cylinders. Kalendar and Oosthuizen [28,29] investigated the effects of dimensionless parameter $w / h$ ratios in the range 0.25 to 1 , Rayleigh numbers in the range $1 \times 10^{3}$ to $1 \times 10^{7}$, and inclination angles in the range $0^{\circ}$ to $180^{\circ}$ on the mean Nusselt numbers for different surfaces of square cylinders in the laminar flow region. A correlation equation was developed for the rate of heat transfer from the entire cylinder. In addition, the authors also studied naturally occurring convective heat transfer from inclined square cylinders with the top surfaces exposed with constant wall heat flux boundary conditions, and determined the effects of dimensionless parameter $w / h$ ratios in the range 0.5 to 1 , modified Rayleigh numbers in the range $1 \times 10^{3}$ to $1 \times 10^{6}$, and inclination angles from $0^{\circ}$ to $180^{\circ}$ on the mean Nusselt number for different surfaces of square cylinders in the laminar flow region. Ali [30] investigated convection heat transfer in the region of laminar flow and the transition flow regions of inclined square cylinders with constant heat flux boundary conditions. Five different square cylinders were studied with aspect ratios, $w / h$, 
of $0.08,0.07,0.06,0.04$, and 0.025 at angles of $30^{\circ}, 45^{\circ}$, and $60^{\circ}$ from the horizontal axis, and a correlation equation for average and local Nusselt numbers was developed.

The effect of different types of fin array and orientation on the natural convective transfer of heat from a square cylinder was considered in the design of pin type heat sinks. An experimental study of the natural convective transfer of heat from heat sinks employing different arrangements and orientations of pin fins was conducted by Huang et al. [31,32]. Their results show that the nature of that transfer differs depending on the orientation and the arrangement of the pin fin heat sink.

Recently, two books on convective transfer of heat from inclined and vertical short cylinders have been published by Oosthuizen and Kalendar [33] and Boetcher [34]. These two books document and summarize the work on heat transfer from different types of cylinders of different sizes, with different parameters, flow types, and forms of correlation equation.

The primary objective of this current work is to understand the influence a relatively small size-to-height ratio for a cuboid $(w / h)$ with different boundary conditions on the mean of the heat transfer rate and interaction of three-dimensional flow over the surfaces at various heat flux Rayleigh numbers and Rayleigh numbers when the cuboid is in various positions at angles between $0^{\circ}$ (pointing upward) and $180^{\circ}$ (pointing downward), as shown in Figure 2. Furthermore, the development of correlation equations to calculate the rate of heat transfer from an inclined slender cuboid positioned on a flat adiabatic base will be helpful in practical applications in the field of thermal engineering.

\section{Numerical Solution Procedures}

The equations governing the solution domain shown in Figure 3 were solved using ANSYS-FLUENT software in terms of dimensionless parameters; taking the height, $h$, of the slender cuboid as the normalizing scale of length, for the temperature scales; taking $q_{w}^{\prime} h / k$ as the constant wall heat flux boundary condition; and $T_{H}-T_{F}$ as the constant wall temperature boundary condition, with $T_{F}$ being temperature of the undisturbed fluid far from the slender cuboid. The solution procedures and the governing equations were adopted from our previous studies (see Kalendar and Oosthuizen [28,29]). The flow was assumed steady, laminar, and symmetrical around the vertical center-plane, and the properties of the fluid were assumed constant except for the change in density with temperature which was handled using the Boussinesq approach. For the case of constant wall heat flux (CWF), the dimensionless parameters subject to the imposed boundary conditions are detailed below. The reference velocity is defined as

$$
u_{r}=\frac{\alpha}{h} \sqrt{R a^{*} P r}
$$

where $\operatorname{Pr}$ denotes the Prandtl number and the heat flux Rayleigh number based on $h$ is denoted as $R a^{*}$, i.e.,

$$
R a^{*}=\frac{\beta g q_{S}^{\prime} h^{4}}{k v \alpha}
$$

The subsequent dimensionless variables were then defined

$$
X=\frac{x}{h}, Y=\frac{y}{h}, Z=\frac{z}{h}, U_{x}=\frac{u_{x}}{u_{r}}, U_{Y}=\frac{u_{y}}{u_{r}}, U_{Z}=\frac{u_{z}}{u_{r}}, P=\frac{\left(P-P_{F}\right)}{\mu u_{r}}, \theta=\frac{\left(T-T_{F}\right)}{q_{S}^{\prime} h / k}
$$

where $T$ denotes the temperature, $q_{S}^{\prime}$ is the constant wall heat flux and $T_{F}$ is the temperature of the fluid far from the slender cuboid. The Cartesian coordinates of the symmetrical domain of the slender cuboid are as follows: the $z$-coordinate is assumed to point vertically upward and $x$ - and $y$-coordinates are assumed to be in the horizontal plane, as shown in Figure 3. The details of the mathematical equations and numerical procedure involved in this study can be found in [33]. The governing equations of these dimensionless variables are

$$
\frac{\partial U_{X}}{\partial X}+\frac{\partial U_{Y}}{\partial Y}+\frac{\partial U_{Z}}{\partial Z}=0
$$




$$
\begin{gathered}
U_{X} \frac{\partial U_{X}}{\partial X}+U_{Y} \frac{\partial U_{X}}{\partial Y}+U_{Z} \frac{\partial U_{X}}{\partial Z}=\sqrt{\frac{P r}{R a^{*}}}\left(-\frac{\partial P}{\partial X}+\frac{\partial^{2} U_{X}}{\partial X^{2}}+\frac{\partial^{2} U_{X}}{\partial Y^{2}}+\frac{\partial^{2} U_{X}}{\partial Z^{2}}\right)+\theta \sin \varphi \\
U_{X} \frac{\partial U_{Y}}{\partial X}+U_{Y} \frac{\partial U_{Y}}{\partial Y}+U_{Z} \frac{\partial U_{Y}}{\partial Z}=\sqrt{\frac{P r}{R a^{*}}}\left(-\frac{\partial P}{\partial Y}+\frac{\partial^{2} U_{Y}}{\partial X^{2}}+\frac{\partial^{2} U_{Y}}{\partial Y^{2}}+\frac{\partial^{2} U_{Y}}{\partial Z^{2}}\right) \\
U_{X} \frac{\partial U_{Z}}{\partial X}+U_{Y} \frac{\partial U_{Z}}{\partial Y}+U_{Z} \frac{\partial U_{Z}}{\partial Z}=\sqrt{\frac{P r}{R a^{*}}}\left(-\frac{\partial P}{\partial Z}+\frac{\partial^{2} U_{Z}}{\partial X^{2}}+\frac{\partial^{2} U_{Z}}{\partial Y^{2}}+\frac{\partial^{2} U_{Z}}{\partial Z^{2}}\right)+\theta \cos \varphi \\
U_{X} \frac{\partial \theta}{\partial X}+U_{Y} \frac{\partial \theta}{\partial Y}+U_{Z} \frac{\partial \theta}{\partial Z}=\sqrt{\frac{1}{R a^{*} P r}}\left(\frac{\partial^{2} \theta}{\partial X^{2}}+\frac{\partial^{2} \theta}{\partial Y^{2}}+\frac{\partial^{2} \theta}{\partial Z^{2}}\right)
\end{gathered}
$$

For the case of the boundary condition at a constant wall temperature (CWT), the following changes are made:

The heat flux Rayleigh number, $R a^{*}$, is replaced by the Rayleigh number, $R a$, where

$$
R a=\frac{\beta g\left(T_{H}-T_{F}\right) h^{3}}{v \alpha}
$$

$q_{s}^{\prime} h / k$ is replaced by $T_{H}-T_{F}$ as the scale for the temperature.

The boundary conditions and a schematic illustration of the solution domain are presented in Figure 3. The boundary conditions are described as follows:

(i) On the plane of symmetry (SINDLMEFOTS), the normal dimensionless velocity is set to zero, the gradients of the other velocity components and temperature normal to the plane of symmetry are also set to zero.

(ii) On the adiabatic base (NBAFEGCDN), the boundary conditions imposed on all dimensionless velocities set the values of those velocities to zero and the dimensionless temperature normal to the adiabatic surface is set to zero.

(iii) On the other planes of the solution domain, both the dimensionless velocity components in the plane and the dimensionless temperature are set to zero.

(iv) On the slender cuboid surfaces, the dimensionless velocity components are equal to zero and the dimensionless temperature normal to the surfaces is set to minus one for a constant wall heat flux boundary condition, while dimensionless temperature normal to the surfaces is set to zero for the imposed constant wall temperature boundary condition for surfaces.

The mesh of the solution domain was generated using quad/map cells to produce a fine mesh near the surfaces of the slender cuboid using GAMBIT commercial software. A varied grid scattering was adopted in all planes parallel and normal to the direction of flow. Near to the surfaces of the slender cuboid and in the boundary layer regions, it was necessary to increase the number of grid points to augment the accuracy of the results obtained. A grid independent study was conducted and the mean of the Nusselt number results for the complete slender cuboid - and for the individual surfaces of the cuboid at different Rayleigh numbers and orientations to the vertical-were obtained within $1 \%$ of the mean Nusselt number, irrespective of the number of grid points used as shown in Table 1. These results are for the cases of an inclined and vertical slender cuboid, with angles ranging between vertically upward and downward for dimensionless width, $W$, set to 0.25 and for different Rayleigh numbers. The number of nodes used to obtain these results was more than 1,063,120. From the results, it was noted that greater refinement of the grid points had no significant effect on the mean of the Nusselt number. Therefore, the simulation used a number of nodes which was always greater than $10^{6}$, but varied depending on the Rayleigh numbers and the size of the model. The positions in the solution domain of the outer surfaces, shown in Figure 3, in relation to the hot surfaces of the slender cuboid, were tested and selected to ensure that the results of the heat transfer were not affected. 


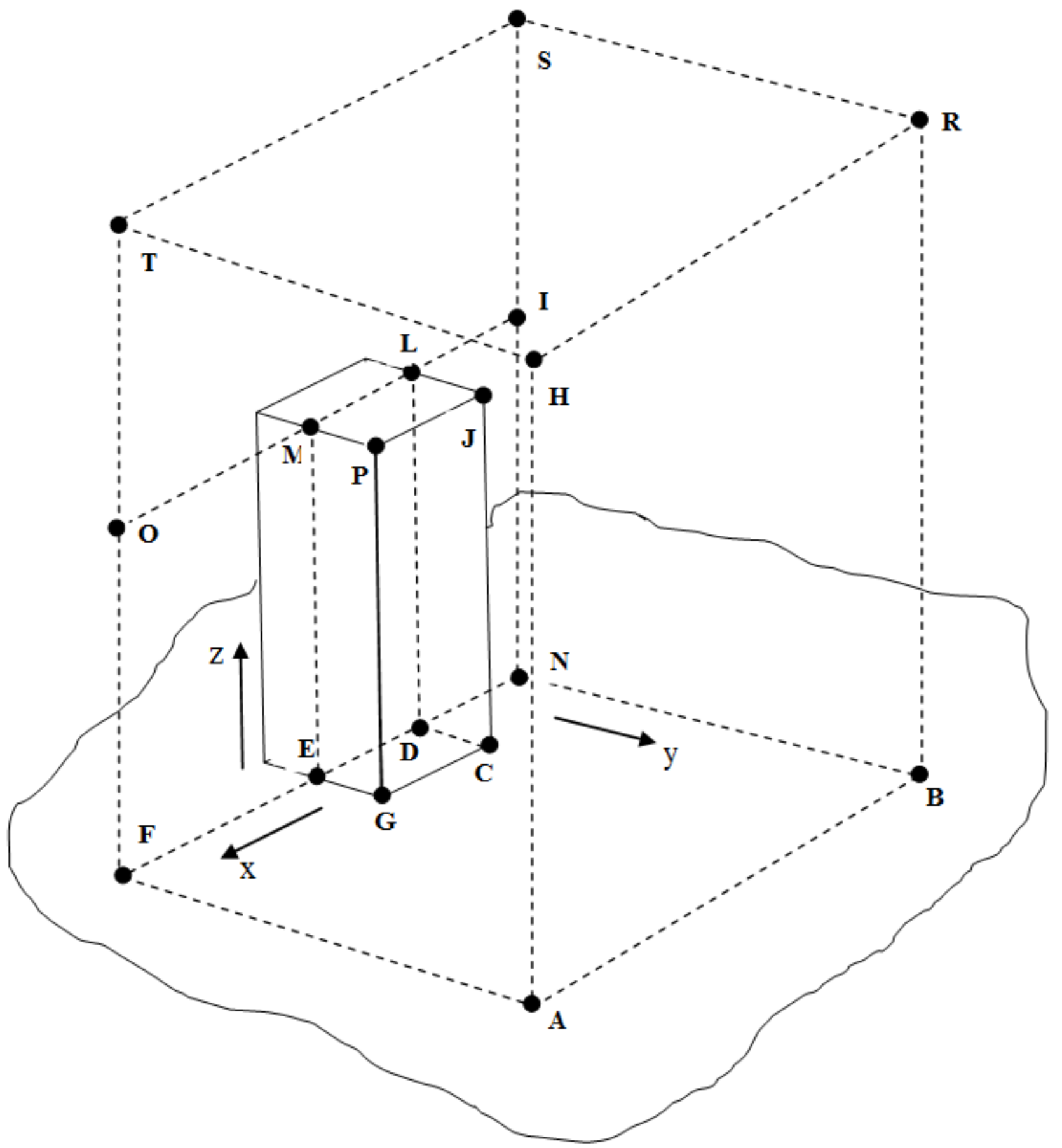

Figure 3. Schematic of the solution domain simulated in this work.

The mean Nusselt numbers for the entire, left, right and front heated surfaces of the modeled slender cuboid for cases with constant wall heat flux (CWF) and constant wall temperature (CWT) boundary conditions are described in Table 2. 
Table 1. Results of grid independent study.

\begin{tabular}{|c|c|c|c|c|c|c|c|c|c|c|c|}
\hline $\begin{array}{c}\text { Rayleigh } \\
\text { No., } R a\end{array}$ & $\begin{array}{c}\text { Inclination } \\
\text { Angle, } \varphi\end{array}$ & $\begin{array}{l}\text { No. of } \\
\text { Nodes }\end{array}$ & $N u_{L}$ & $N u_{R}$ & $N u_{F}$ & $N u_{m}$ & $\begin{array}{c}\text { Rayleigh } \\
\text { No., } R a\end{array}$ & $N u_{L}$ & $N u_{R}$ & $N u_{F}$ & $N u_{m}$ \\
\hline \multirow{24}{*}{$1 \times 10^{7}$} & \multirow{8}{*}{$0^{\circ}$} & 132300 & 31.3 & 31.3 & 31.63 & 30.05 & \multirow{24}{*}{$1 \times 10^{3}$} & 4.65 & 4.65 & 4.55 & 4.6 \\
\hline & & 195600 & 31.4 & 31.4 & 31.73 & 30.2 & & 4.66 & 4.66 & 4.55 & 4.61 \\
\hline & & 321444 & 31.4 & 32.06 & 31.55 & 30.34 & & 4.66 & 4.64 & 4.58 & 4.62 \\
\hline & & 508320 & 31.41 & 31.89 & 31.3 & 30.18 & & 4.65 & 4.63 & 4.6 & 4.63 \\
\hline & & 761760 & 31.31 & 31.65 & 31.27 & 30.07 & & 4.66 & 4.64 & 4.59 & 4.63 \\
\hline & & 1063120 & 31.17 & 31.2 & 31.07 & 29.84 & & 4.68 & 4.68 & 4.58 & 4.63 \\
\hline & & 1194600 & 30.84 & 30.94 & 30.83 & 29.56 & & 4.68 & 4.68 & 4.6 & 4.64 \\
\hline & & 1538550 & 30.84 & 30.84 & 30.84 & 29.3 & & 4.68 & 4.68 & 4.6 & 4.64 \\
\hline & \multirow{8}{*}{$90^{\circ}$} & 132300 & 10.84 & 30.94 & 30.83 & 29.56 & & 3.39 & 5.95 & 5.09 & 5.04 \\
\hline & & 206974 & 10.84 & 30.84 & 30.84 & 29.3 & & 3.4 & 5.95 & 5.09 & 5.04 \\
\hline & & 336510 & 10.55 & 32.14 & 39.37 & 31.11 & & 3.39 & 5.93 & 5.13 & 5.07 \\
\hline & & 528654 & 10.28 & 32.29 & 38.4 & 30.67 & & 3.38 & 5.91 & 5.14 & 5.07 \\
\hline & & 788478 & 10.32 & 32.28 & 38.25 & 30.63 & & 3.4 & 5.93 & 5.13 & 5.07 \\
\hline & & 1097052 & 10.45 & 31.77 & 37.82 & 30.33 & & 3.41 & 5.977 & 5.12 & 5.07 \\
\hline & & 1233063 & 10.96 & 31.18 & 37.05 & 29.84 & & 3.47 & 5.99 & 5.17 & 5.1 \\
\hline & & 1584308 & 11.06 & 31.02 & 36.91 & 29.75 & & 3.43 & 6 & 5.17 & 5.1 \\
\hline & \multirow{8}{*}{$180^{\circ}$} & 132300 & 29.27 & 29.26 & 29.91 & 29.86 & & 4.26 & 4.26 & 4.24 & 4.51 \\
\hline & & 195600 & 29.15 & 29.15 & 29.78 & 29.88 & & 4.27 & 4.27 & 4.24 & 4.51 \\
\hline & & 321444 & 28.99 & 29.27 & 29.38 & 29.81 & & 4.26 & 4.23 & 4.26 & 4.52 \\
\hline & & 508320 & 28.91 & 29.25 & 28.99 & 29.66 & & 4.25 & 4.22 & 4.27 & 4.52 \\
\hline & & 761760 & 28.86 & 29.1 & 28.87 & 29.57 & & 4.27 & 4.24 & 4.26 & 4.53 \\
\hline & & 1063120 & 28.87 & 28.87 & 28.47 & 29.43 & & 4.28 & 4.28 & 4.25 & 4.53 \\
\hline & & 1194600 & 28.81 & 28.81 & 28.86 & 29.33 & & 4.33 & 4.33 & 4.32 & 4.59 \\
\hline & & 1538550 & 28.82 & 28.81 & 28.84 & 29.29 & & 4.29 & 4.29 & 4.29 & 4.54 \\
\hline
\end{tabular}

Table 2. Mean Nusselt number for the entire, left, right, and front heated surfaces of the slender cuboid for cases with constant wall heat flux (CWF) boundary condition and constant wall temperature (CWT) boundary conditions.

\begin{tabular}{rrr}
\hline Constant Wall Temperature (CWT) & Constant Wall Heat Flux (CWF) & Equation Number \\
\hline$N u$ & $=\frac{q_{S}^{\prime} h}{k\left(\bar{T}_{S}-T_{F}\right)}$ & $N u_{m}=\frac{\bar{q}_{S}^{\prime} h}{k\left(T_{H}-T_{F}\right)}$ \\
$N u_{\text {left }}=\frac{q_{S \text { left }}^{\prime} h}{k\left(\bar{T}_{S} \text { left }-T_{F}\right)}$ & $N u_{L}=\frac{\bar{q}_{L}^{\prime} h}{k\left(T_{H}-T_{F}\right)}$ \\
$N u_{\text {right }}=\frac{q_{S}^{\prime} \text { right } h}{k\left(\bar{T}_{S} \text { right }-T_{F}\right)}$ & $N u_{R}=\frac{\bar{q}_{R}^{\prime} h}{k\left(T_{H}-T_{F}\right)}$ \\
$N u_{\text {front }}$ & $=\frac{q_{S}^{\prime} \text { front }}{k\left(\bar{T}_{S \text { front }}-T_{F}\right)}$ & $N u_{F}=\frac{\bar{q}_{F}^{\prime} h}{k\left(T_{H}-T_{F}\right)}$
\end{tabular}

$\bar{T}_{S}, \bar{T}_{S \text { left }}, \bar{T}_{S \text { right }}, \bar{T}_{S \text { front }}$ are the average temperatures for the entire, left, right and front heated surfaces of the slender cuboid, respectively and $\bar{q}_{S}^{\prime}, \bar{q}_{L}^{\prime}, \bar{q}_{R}^{\prime}, \bar{q}_{F}^{\prime}$ are the mean heat fluxes from the entire, left, right, and front heated surfaces of the slender cuboid respectively.

\section{Results and Discussion}

The solution involves the parameters defined below:

- The $R a^{*}$, the heat flux Rayleigh number, dependent on the height, $h$, of the heated slender cuboid, is set as the length scale, and $q_{w}^{\prime} h / k$ is set as the temperature scale.

- The $R a$, Rayleigh number, dependent on the height, $h$, of the heated slender cuboid, is set as the length scale, and the global difference in temperature $T_{H}-T_{F}$ is set as the temperature scale.

- $\quad$ The dimensionless width of the slender cuboid, $W=w / h$, i.e., $W<<h$.

- The Prandtl number, Pr.

- The positions of the slender cuboid, $\varphi$, in relation to the vertical. 


\subsection{Validation}

A broad range of the aforementioned governing parameters were considered: $\varphi$ at $0^{\circ}, 45^{\circ}, 90^{\circ}, 135^{\circ}$, and $180^{\circ} ; R a^{*}$ in the range $10^{3}$ to $10^{9} ; R a$ in the range $10^{3}$ to $10^{7} ; \mathrm{W}$ in the range 0.25 to 0.05 ; but the only $\operatorname{Pr}$ number used was 0.7 , that of air.

The model was previously validated by Kalendar and Oosthuizen [29] who compared numerical, correlation equation, and experimental results for constant temperature boundary conditions and found that they exhibited fairly good agreement. Further validation was carried out using the correlation equation and experimental results obtained by Ali [30] for a square cylinder in air with constant heat flux boundary conditions of $w / h=0.08$ and at angles of $60^{\circ}\left(30^{\circ}\right.$ from the horizontal) and $45^{\circ}$ where the bottom and top surfaces were adiabatic. Representative results for this condition are shown in Figure 4. It can be seen that there is good agreement on the range of accuracy between the correlation equation and experimental results obtained by Ali [30] and the present numerical results. We believe that the differences between the mean Nusselt numbers obtained by Ali [30] and the present numerical results at higher values of Rayleigh numbers are due to the uncertainty in Ali's [30] results, which was in the range $\pm 15 \%$.

\subsection{Evaluation of the Width Effect of a Slender Cuboid}

The variations in the mean of the Nusselt number of all heated surfaces of the slender cuboid, $N u$, versus its dimensionless width, $W$, at different positions, $\varphi$, and heat flux Rayleigh numbers, $R a^{*}$, are presented in Figure 5, while the variations in the mean of the Nusselt number of all the heated surfaces of the slender cuboid, $N u_{m}$, versus its dimensionless width, $W$, at different positions, $\varphi$, and Rayleigh numbers, $R a$, are shown in Figure 6. From these figures, it can be seen that the mean of the Nusselt number decreases with increasing dimensionless width, $W$. When heat flux Rayleigh number, $R a^{*}$, and Rayleigh number, $R a$, reach their highest values, the position of the slender cuboid, $\varphi$, has a very marked influence on the value of the mean Nusselt number. This is due to the fact that the boundary layer thickness is greater at lower Rayleigh numbers than at higher Rayleigh numbers and the flow interaction over the surfaces of the slender cuboid reduces as the boundary layer becomes thicker. The thicker boundary layer and the flow interaction over the surfaces of the slender cuboid reduces the influence of three-dimensional flows and heat transfer enhancement near the edges of the slender cuboid, the so-called 'edge effect'. When the Rayleigh numbers are high, the boundary layer is thinner and the flow interaction over the surfaces of the slender cuboid increases, which augments the edge effects, the influence of three-dimensional flows, and the heat transfer enhancement near the edges of the slender cuboid. Moreover, when the heat flux Rayleigh number is lower (e.g., below $10^{5}$ ) and dimensionless width is greater than 0.15 , a very small reduction in the mean Nusselt number is noted. However, at increased heat flux Rayleigh numbers, the change in the mean Nusselt number behaves differently. At higher heat flux Rayleigh numbers, the mean Nusselt number reaches its lowest value, which occurs when the slender cuboid is in a horizontal position. The mean Nusselt number maintains its value for all values considered for $R a, R a^{*}$, and $W$ when the inclination angle $\varphi=0^{\circ}$ (the slender cuboid is pointing upward), and when $\varphi=180^{\circ}$ (the slender cuboid is pointing downward). Furthermore, the simulations show that the mean Nusselt number is almost the same at higher values considered for $W$ and for all values considered for $R a$ and $R a^{*}$ when the inclination angles, $\varphi$, are $45^{\circ}$ and $135^{\circ}$. The mean Nusselt number is at a maximum when $\varphi=90^{\circ}$, when the slender cuboid is in the horizontal position, for all the values considered for $R a$ and $W$, except at higher Rayleigh number $R a=10^{7}$ and heat flux Rayleigh number $R a^{*} \geq 10^{7}$. The mean Nusselt number decreases for other angles as $W$ increases. This situation will be discussed later. 

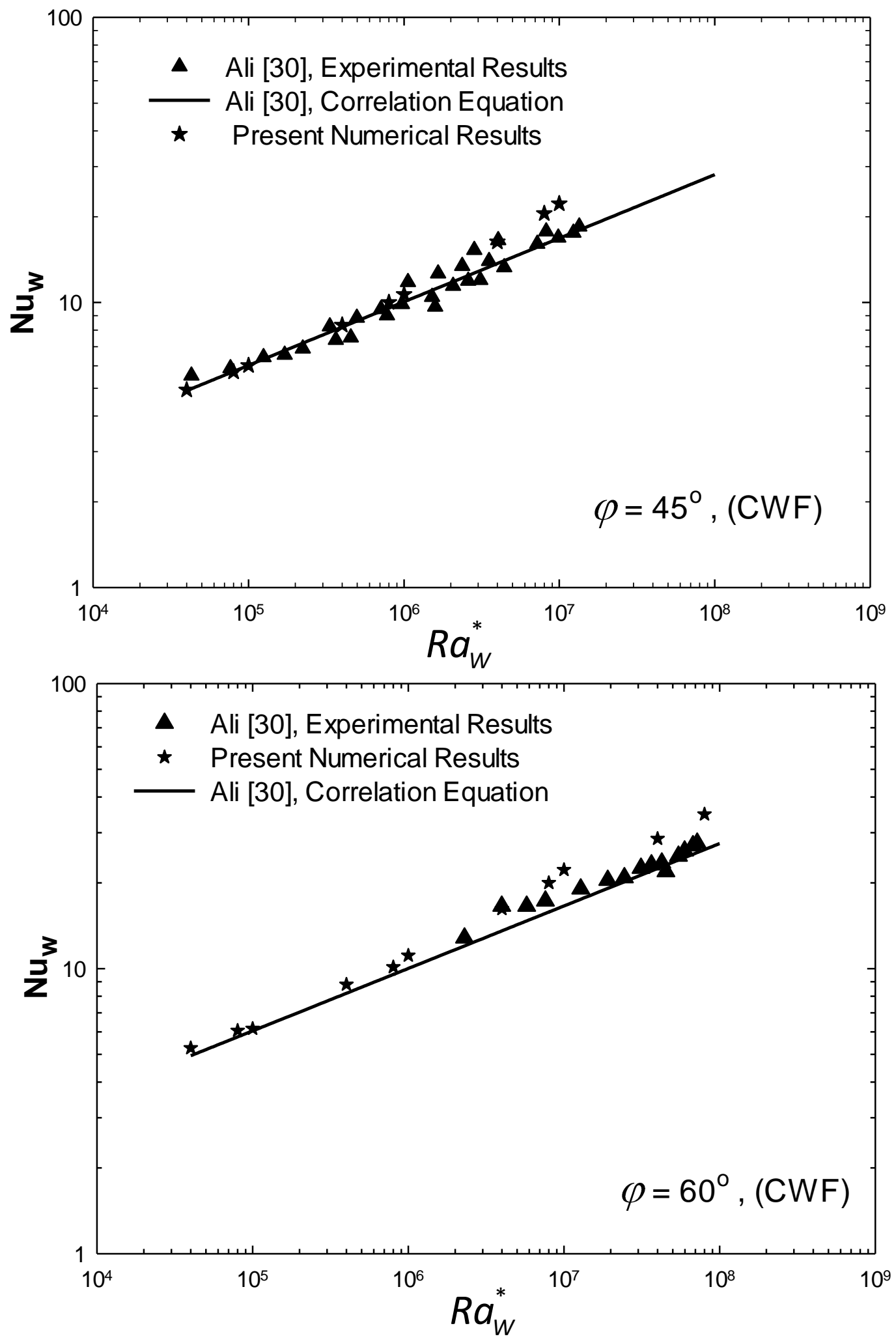

Figure 4. Numerical results of the mean Nusselt number, compared with values obtained from the correlation equations, and with experimental results obtained by Ali [30] for a square cylinder with width ratio $W=0.08$ and inclination angles of $\varphi=60^{\circ}$ (30 from the horizontal) $\varphi=45^{\circ}$ for various values of the heat flux Rayleigh number based on $W$. 


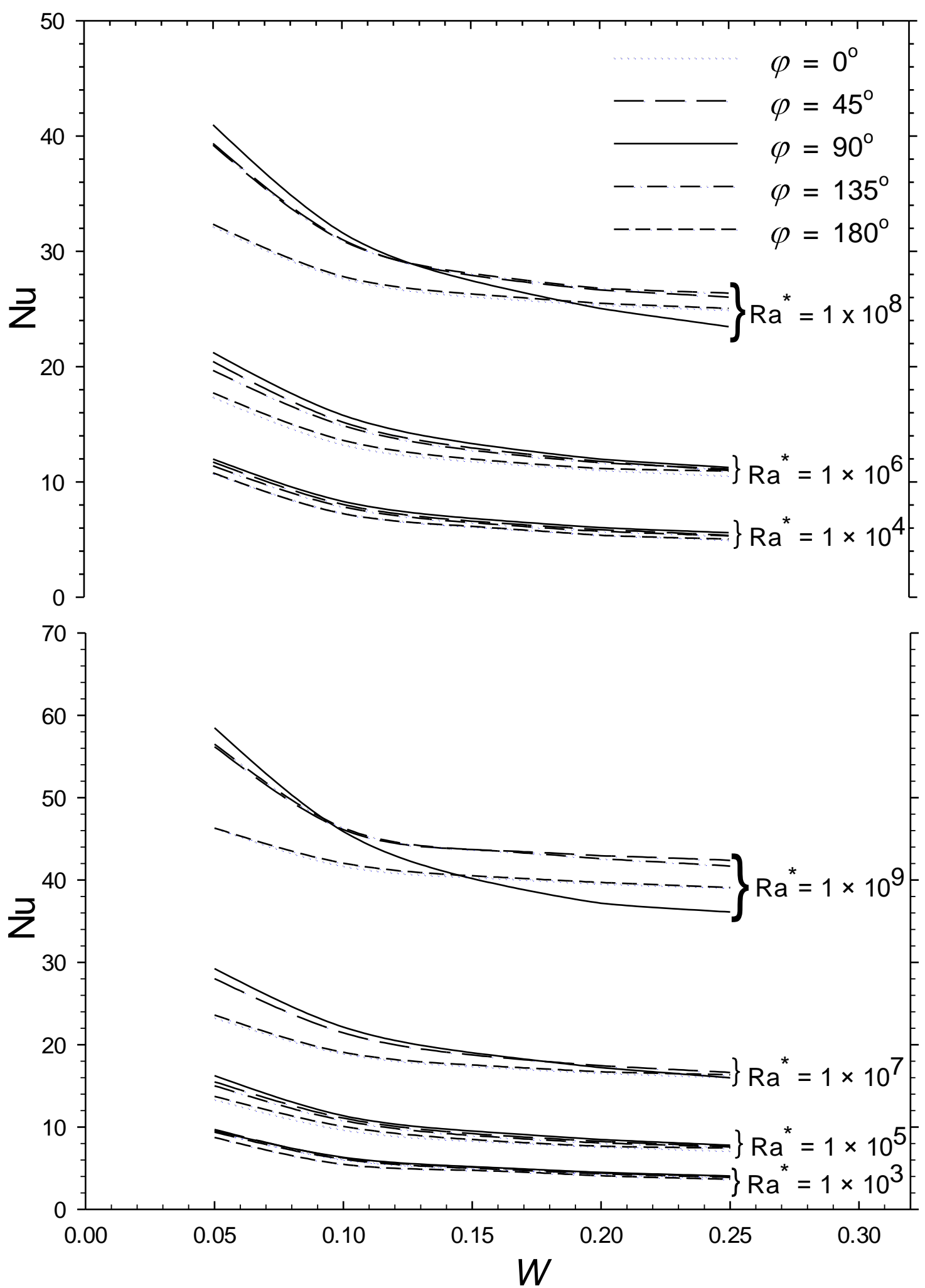

Figure 5. Variations in mean Nusselt number with dimensionless width, $W$, for different values of the Rayleigh number, Ra, and positions, $\varphi$, for all surfaces of the slender cuboid. 

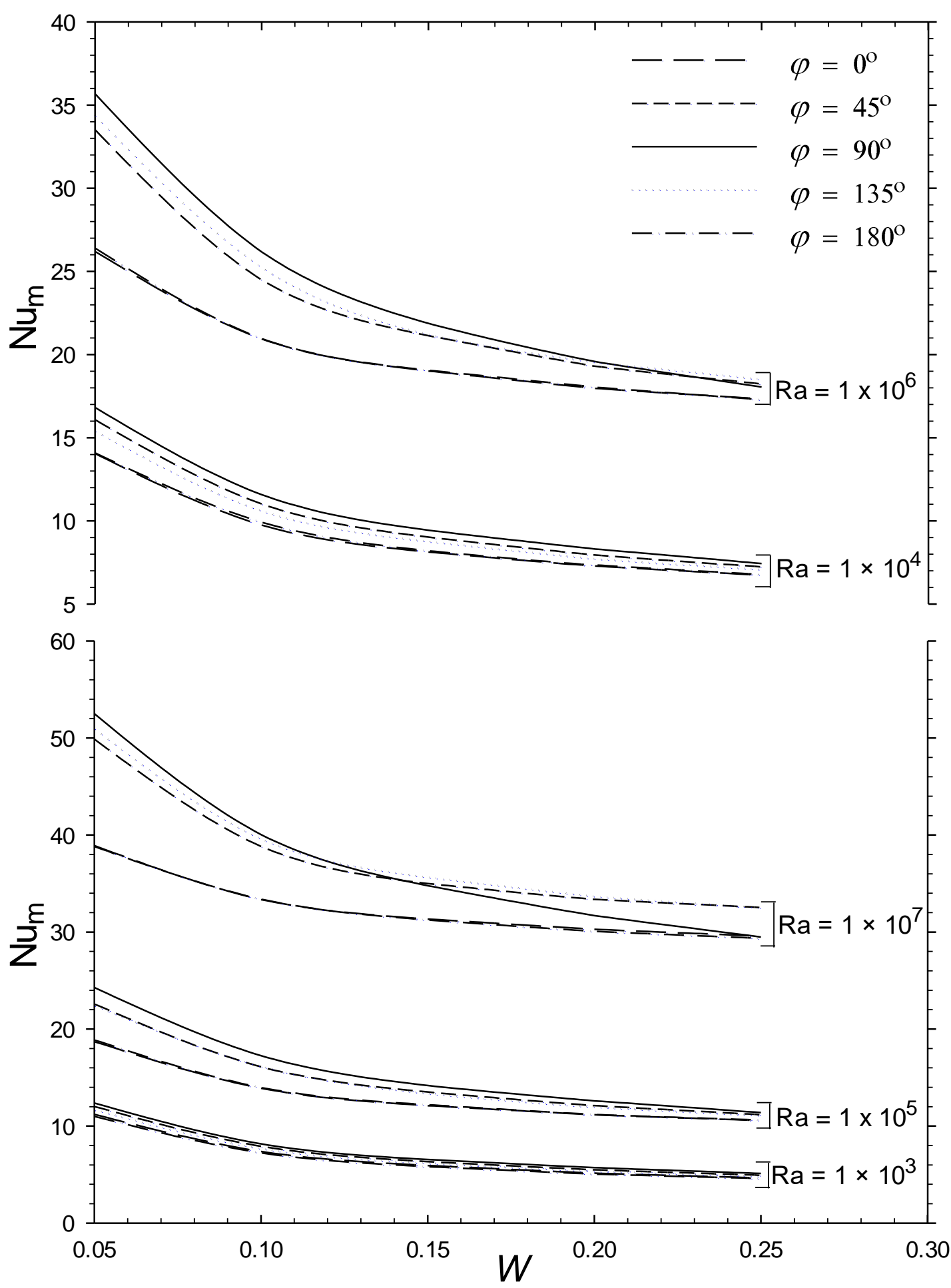

Figure 6. Variations in mean Nusselt number with dimensionless width, $W$, for different values of the heat flux Rayleigh number, $R a^{*}$, and positions, $\varphi$, for all surfaces of the slender cuboid.

The variations in the mean Nusselt number of individual heated surfaces of the slender cuboid, $\left(N u_{\text {left }}, N u_{\text {right }}, N u_{\text {front }}\right)$, versus dimensionless width, $W$, at different positions, $\varphi$, and heat flux Rayleigh numbers, $R a^{*}$, are presented in Figures 7-9, respectively. The rate of heat transfer from the heated top surface of the slender cuboid, being very small compared to that of other surfaces (see Kalendar and Oosthuizen [29]), will not be considered in our discussions. These figures illustrate that the mean Nusselt number for individual heated surfaces of the slender cuboid increases with decreasing dimensionless width, $W$, and the 
values of the mean Nusselt number for individual heated surfaces change with position, $\varphi$, at different heat flux Rayleigh numbers.

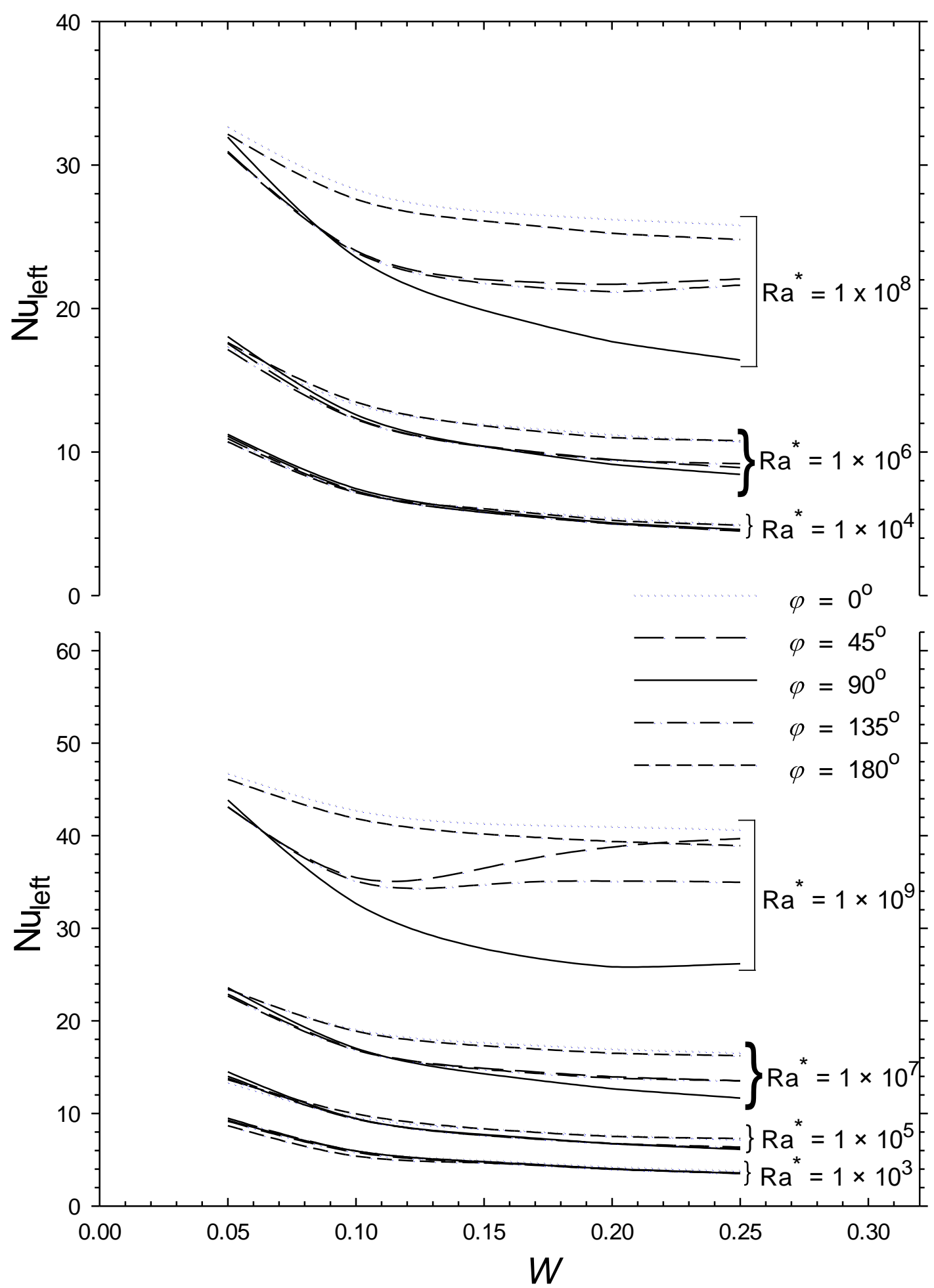

Figure 7. Variations in the mean Nusselt number of the left-side surface of the slender cuboid with dimensionless width, $W$, for different values of the heat flux Rayleigh number, $R a^{*}$, and positions, $\varphi$. 

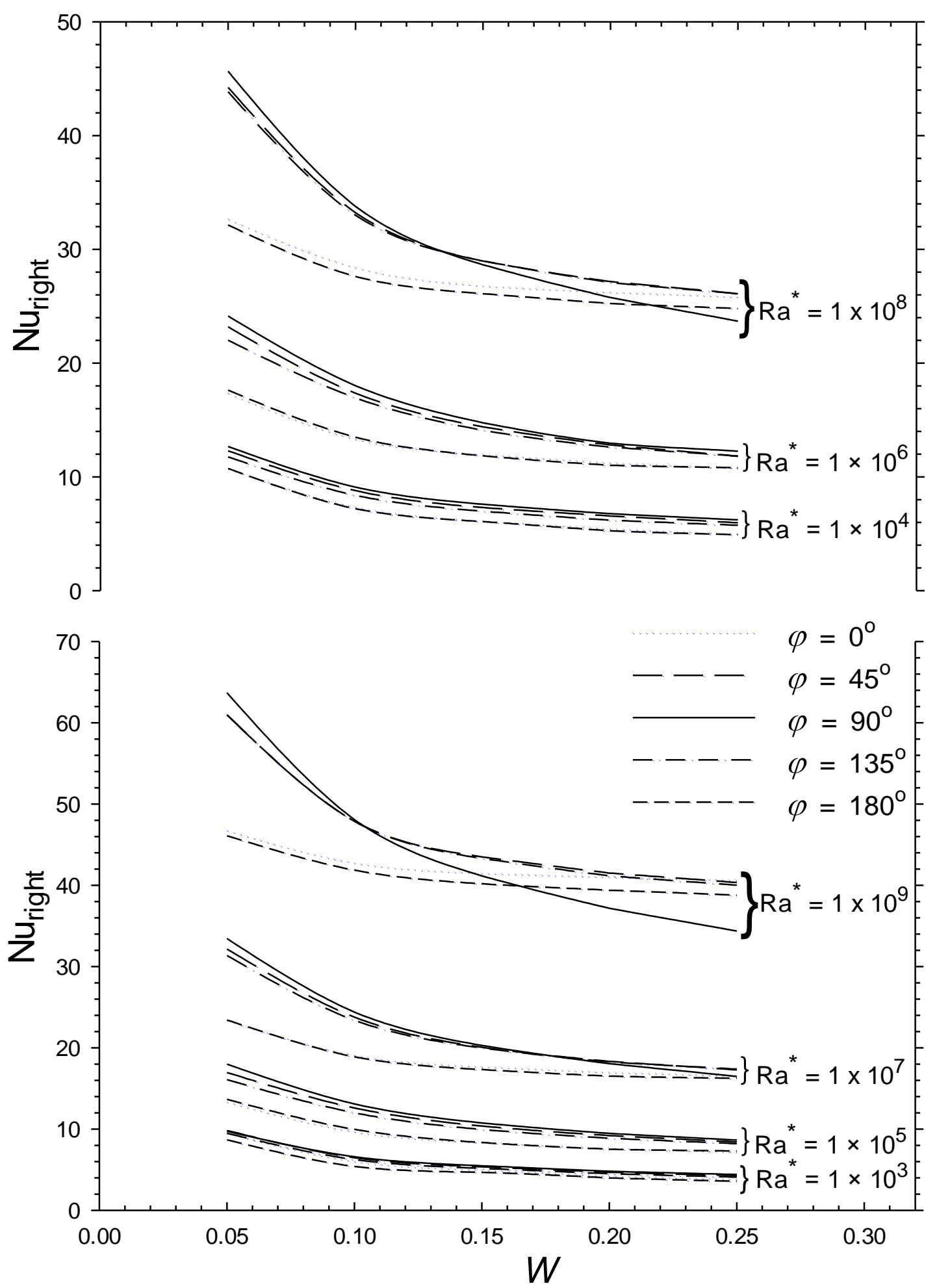

Figure 8. Variations in the mean Nusselt number of the right-side surface of the slender cuboid with dimensionless width, $W$, for different values of the heat flux Rayleigh number, $R a^{*}$, and positions, $\varphi$. 

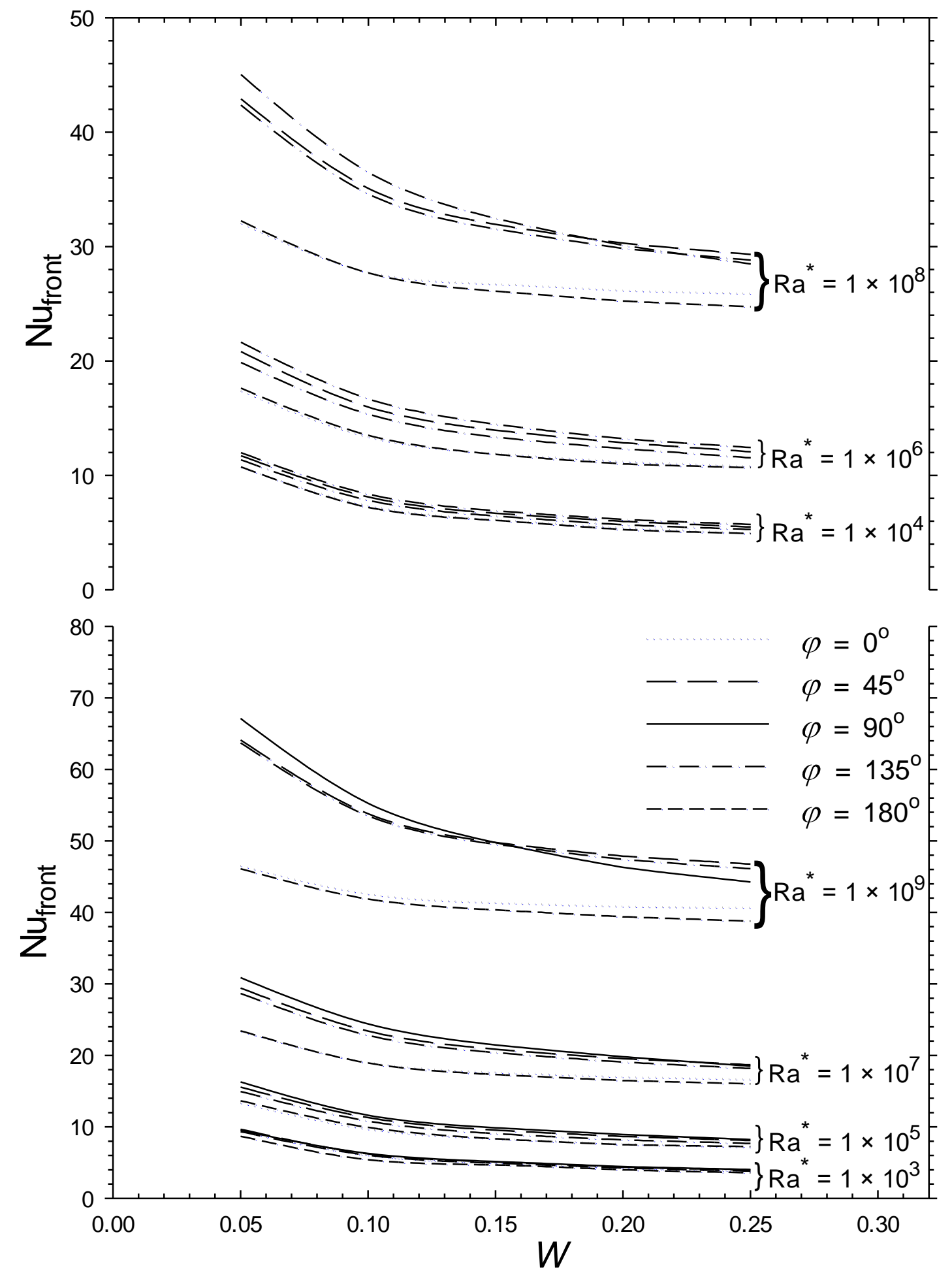

Figure 9. Variations in the mean Nusselt number of the front surface of the slender cuboid with dimensionless width, $W$, for different values of the heat flux Rayleigh number, $R a^{*}$, and positions, $\varphi$.

From Figure 7, for the heated left-side surface of the slender cuboid, it is observed that the mean Nusselt number is inversely proportional to the dimensionless width, and at lower heat flux Rayleigh numbers, below $1 \times 10^{5}$, the effect of the position is almost negligible. At high heat flux Rayleigh numbers, greater than $1 \times 10^{5}$, the mean Nusselt number, $N u_{\text {left }}$, behaves differently for higher values of $W$ than for lower values, while at small dimensionless widths, $W$, lower than 0.1 , the reduction in the mean Nusselt number 
is greater than that when dimensionless width, $W$, is larger than 0.1. For positions of the slender cuboid, $\varphi$ - equal to $0^{\circ}$ and $180^{\circ}$ - the value of the mean Nusselt number is essentially equal for all heat flux Raleigh numbers and dimensionless widths considered, except at heat flux Rayleigh numbers greater than $1 \times 10^{8}$; all positions have an influence on the reduction of the mean Nusselt number. At positions equal to $90^{\circ}$, the mean Nusselt number is essentially equal for low values of the heat flux Raleigh number below $1 \times 10^{5}$ and all dimensionless widths considered. For positions equal to $90^{\circ}$, and at high heat flux Rayleigh numbers greater than $1 \times 10^{5}$, the mean Nusselt number decreases with increasing dimensionless widths.

From Figure 8, for the right-side heated surface of the slender cuboid, it can be seen that the mean Nusselt number, $N u_{\text {right }}$, is inversely proportional to the dimensionless width. When the positions of the slender cuboid, $\varphi$, is equal to $0^{\circ}$ (vertically upward) or $180^{\circ}$ (vertically downward), the values of the mean Nusselt number are essential equal for all heat flux Raleigh numbers and dimensionless widths considered, although at heat flux Rayleigh numbers greater than $1 \times 10^{8}$, the mean Nusselt number has higher values for position $\varphi$ equal to $0^{\circ}$ than for position $\varphi$ equal to $180^{\circ}$. For horizontal positions of the slender cuboid, $\varphi$ equal to $90^{\circ}$, and for low values of heat flux Raleigh numbers below $1 \times 10^{7}$, and all dimensionless widths considered, the mean Nusselt number is higher than that for positions of $\varphi$ equal to $180^{\circ}$. For the position of the slender cuboid where $\varphi$ is set to $90^{\circ}$, and at high heat flux Rayleigh numbers greater than $1 \times 10^{8}$, mean Nusselt numbers are lower than for positions of $\varphi$ equal to $180^{\circ}$ at larger dimensionless widths.

From Figure 9, for the heated front surface of the slender cuboid, it is noted that the mean Nusselt number, $\mathrm{N} u_{\text {front }}$, is inversely proportional to the dimensionless width. At positions of the slender cuboid $\varphi$ equal to $0^{\circ}$ and $180^{\circ}$ the mean Nusselt numbers are almost equal for all dimensionless widths and heat flux Raleigh numbers considered, except at heat flux Rayleigh numbers greater than $1 \times 10^{8}$ and large dimensionless cuboid widths, where the mean Nusselt numbers have higher values for position $\varphi$ equal to $0^{\circ}$ than for position $\varphi$ equal to $180^{\circ}$. At horizontal positions of the slender cuboid when $\varphi$ is equal to $90^{\circ}$, and at the minimum heat flux Raleigh number, $1 \times 10^{3}$, and all dimensionless widths considered, the mean Nusselt numbers do not depend on the positions of the slender cuboid. For cuboid position $\varphi$ equal to $90^{\circ}$ and at higher heat flux Rayleigh numbers greater than $1 \times 10^{4}$, the mean Nusselt number is higher than for a position of $\varphi$ equal to $180^{\circ}$ at all dimensionless widths.

\subsection{Evaluation of the Inclination Angle of a Slender Cuboid}

The variations in mean Nusselt number, $\left(\mathrm{Nu}, \mathrm{N} u_{m}\right)$, for constant temperature boundary conditions and constant heat flux versus angles of inclination, $\varphi$, at different values of the dimensionless width, $W$, heat flux Rayleigh numbers, $R a^{*}$, and Rayleigh numbers, $R a$, are presented in Figures 10 and 11 respectively. These results show that the mean Nusselt numbers for all surfaces of the slender cuboid change differently with angle of inclination, $\varphi$, at different Rayleigh numbers and heat flux Rayleigh numbers increase as the dimensionless width, $W$, decreases. From these figures, it can be seen that there are small changes in the Nusselt number at lower Rayleigh numbers and heat flux Rayleigh numbers and at dimensionless width, $W$, greater than 0.15 for all values of inclination angle, $\varphi$. With higher values of the Rayleigh number and heat flux Rayleigh number, the variations in the mean Nusselt number behave differently when $W$ is high rather than low. 

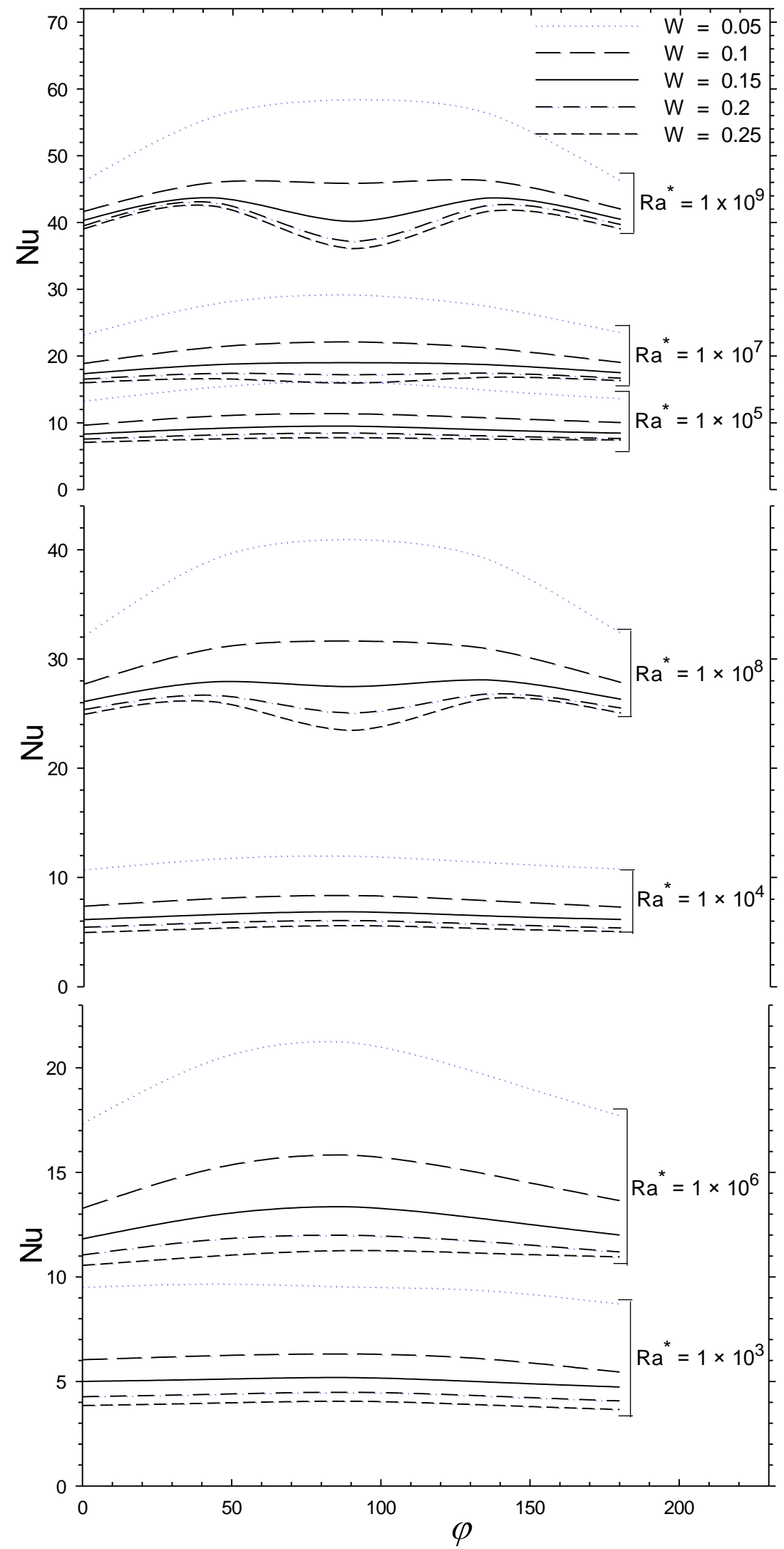

Figure 10. Variations in the mean Nusselt number for a slender cuboid with inclination $\varphi$ for different $R a^{*}$ and $W$. 

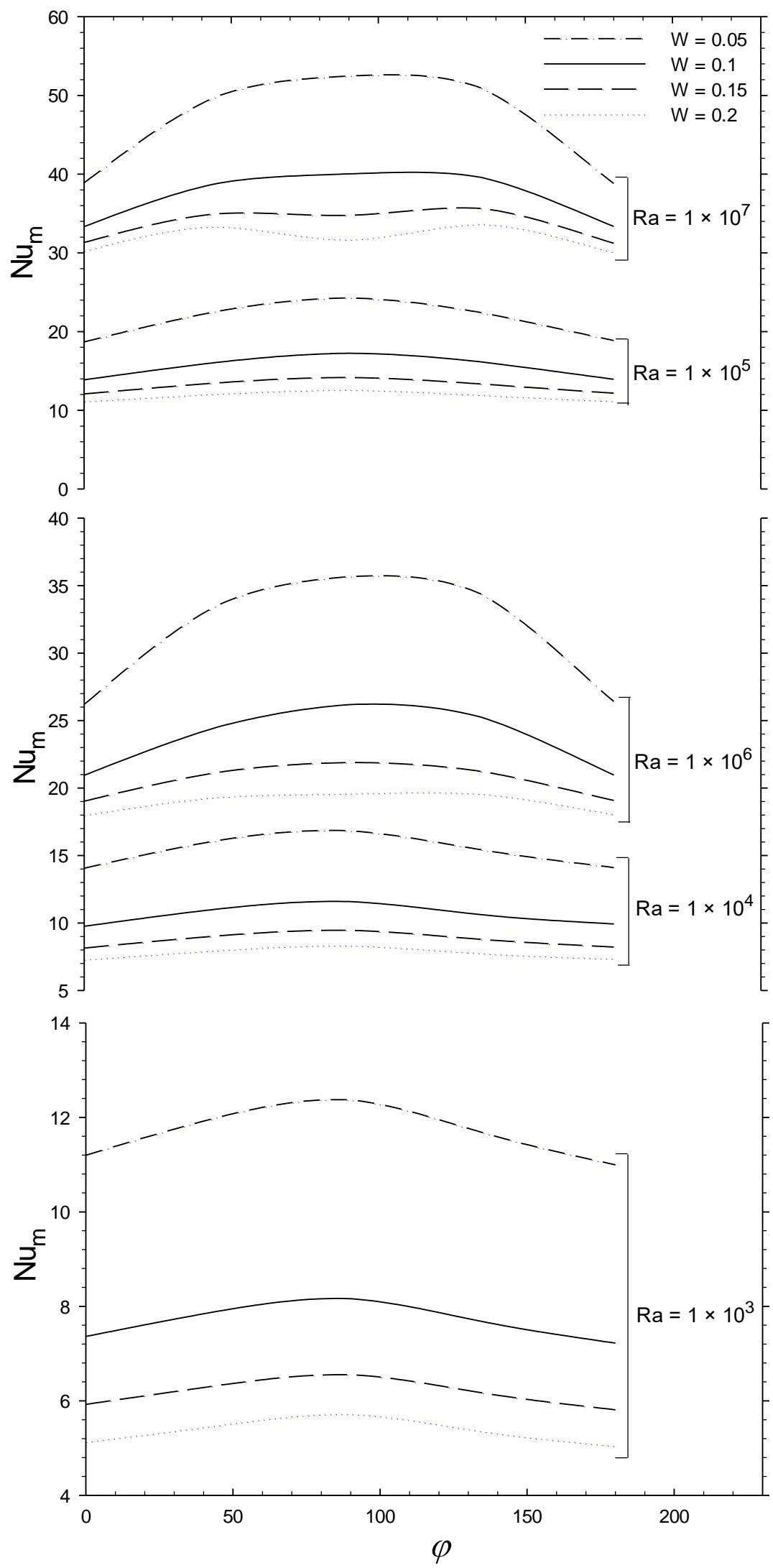

Figure 11. Variations in the mean Nusselt number for a slender cuboid with inclination $\varphi$ for different $R a$ and $W$. 
The variations in mean Nusselt number of the individual surfaces from which the slender cuboid is constructed, $\left(N u_{\text {front }}, N u_{\text {left }}, N u_{\text {right }}, N u_{L}, N u_{R}, N u_{F}\right)$, versus angles of inclination, $\varphi$, at different values of the dimensionless width, $W$, modified Rayleigh numbers, $R a^{*}$, and Rayleigh numbers, $R a$, are shown in Figure 12, Figure 13a,b, Figure 14a,b, and Figure 15 respectively. These results indicate that the mean Nusselt numbers for individual surfaces of the slender cuboid vary differently with inclination angle, $\varphi$, at different heat flux Rayleigh numbers and Rayleigh numbers and increase as, $W$, the dimensionless width, decreases. It is also observed that the mean Nusselt number for individual surfaces of the slender cuboid changes in magnitude with inclination angles, $\varphi$, and is different at lower and higher heat flux Rayleigh numbers and Rayleigh numbers. Furthermore, the maximum and minimum values of the mean Nusselt number for the individual surfaces of the slender cuboid change with the inclination angle and are also affected by the heat flux Rayleigh number and the Rayleigh number.

The variation in the mean Nusselt numbers for individual and all surfaces of the heated slender cuboid, as observed above, is further explained in terms of the development of buoyancy-driven flow over the surfaces. In fact, when the heated slender cuboid is inclined at angles less than $90^{\circ}$, then the buoyancy-driven warm convection flow develops from the heated lower front and right-side surfaces of the slender cuboid and encircles the top and left-side surfaces. This limits the actual temperature gradients of the heated top and left-side surfaces and the adjacent fluid, affecting the heat transfer rates. With inclination angles of $90^{\circ}<\varphi<180^{\circ}$, the buoyancy-driven warm convective flow develops from the top and right-side heated surfaces which affects the rates of heat transfer from the front and left-side heated surfaces of the cuboid. Moreover, when the slender cuboid is placed at an angle to the vertical, a different pressure occurs on each surface, ranging between positive and negative, causing flows over the surfaces of the slender cuboid to interact and consequently affecting heat transfer rates. Developments in the three-dimensional flow close to the edges of the slender cuboid become significant in calculating the rates of heat transfer. Furthermore, when placing the heated slender cuboid at an angle of between $0^{\circ}<\varphi<180^{\circ}$, the pressure on the left-side surface is negative which induces a flow from the undisturbed fluid towards the central section of the left-side surface and enhances the heat transfer rates near the edges. The negative pressure acting on the left-side surface reduces the flow and thickness of the thermal boundary layers over the front, top, and left-side surfaces, affecting the heat transfer rates. At the same time, the pressure on the right-side surface is positive causing flow outward from the center towards the right-side surface edges, which in turn affects the heat transfer rates.

\subsection{Evaluation of the Local Nusselt Number}

The local dimensionless temperature distribution over the heated right-side, leftside, and front surfaces of the slender cuboid for different positions between vertically downward and vertically upward with $R a^{*}=1 \times 10^{4}, R a^{*}=1 \times 10^{8}$, and $W=0.15$ are shown in Figures 16 and 17. The variations in dimensionless temperature distribution over these heated surfaces are caused by the variations in flow patterns in three-dimensions and the complex buoyancy-driven flow interactions over the heated surfaces of the slender cuboid which influence the local Nusselt number over those surfaces. Furthermore, Figure 18 shows the variations in local Nusselt number over the right-side, front, and left-side surfaces of the slender cuboid with distance (dimensionless) along the horizontal centerline $(\mathrm{z} / \mathrm{h}=0.5)$ at different positions between vertically downward and vertically upward for $R a^{*}=1 \times 10^{6}$ and $W=0.15$. This figure shows that the highest values of the local Nusselt number are found near the corners of the slender cuboid and that the cuboid positions influence the local Nusselt number over side surfaces which are heated. 

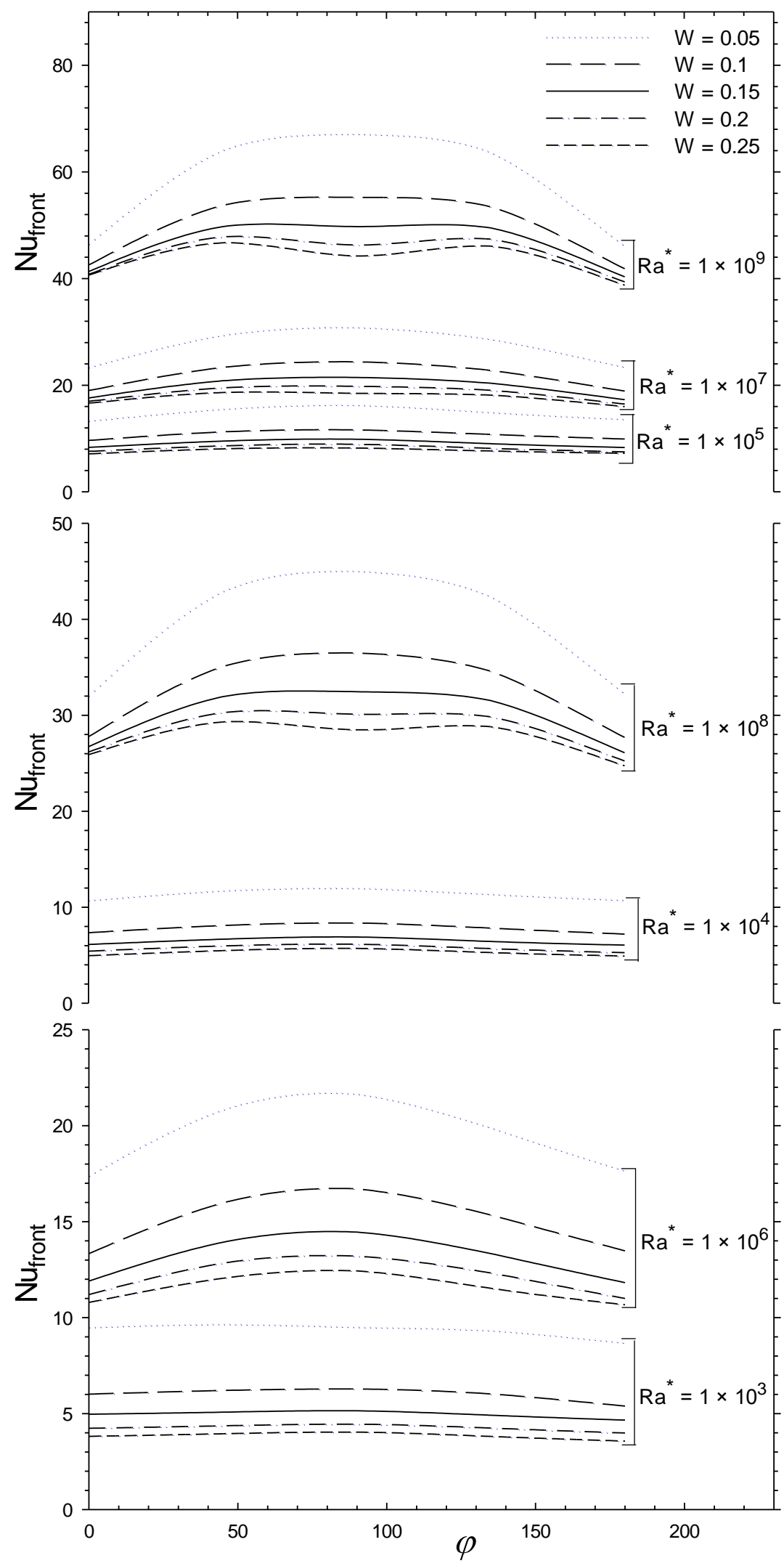

Figure 12. Variations in the mean Nusselt number for the front of a slender cuboid with inclination $\varphi$ for different $R a^{*}$ and $W$. 

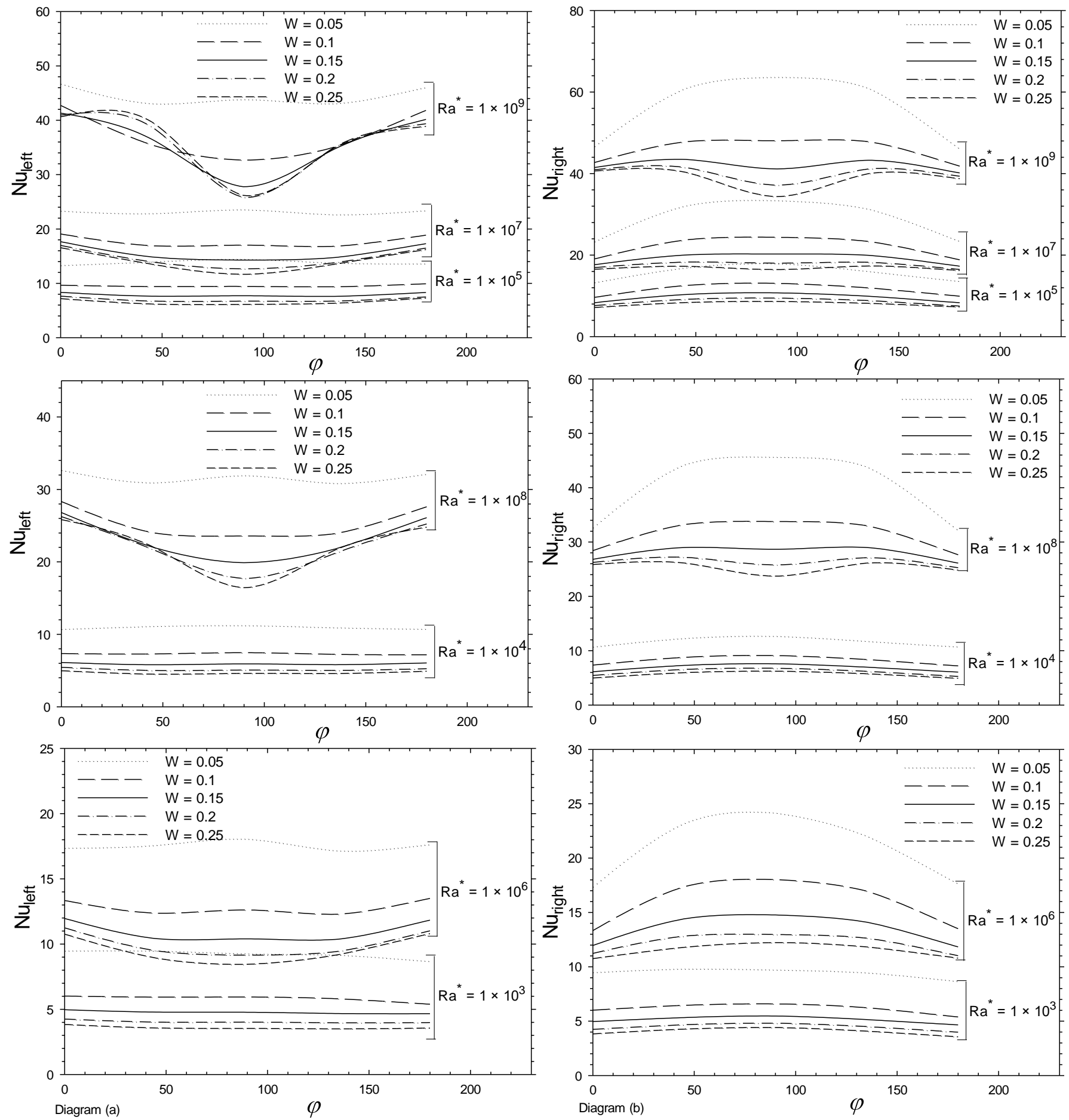

Figure 13. Variations in the mean Nusselt number for the left-side and right-side surfaces of a slender cuboid with inclination $\varphi$ for different $R a^{*}$ and $W$ for (a) left-side and (b) right-side surfaces. 

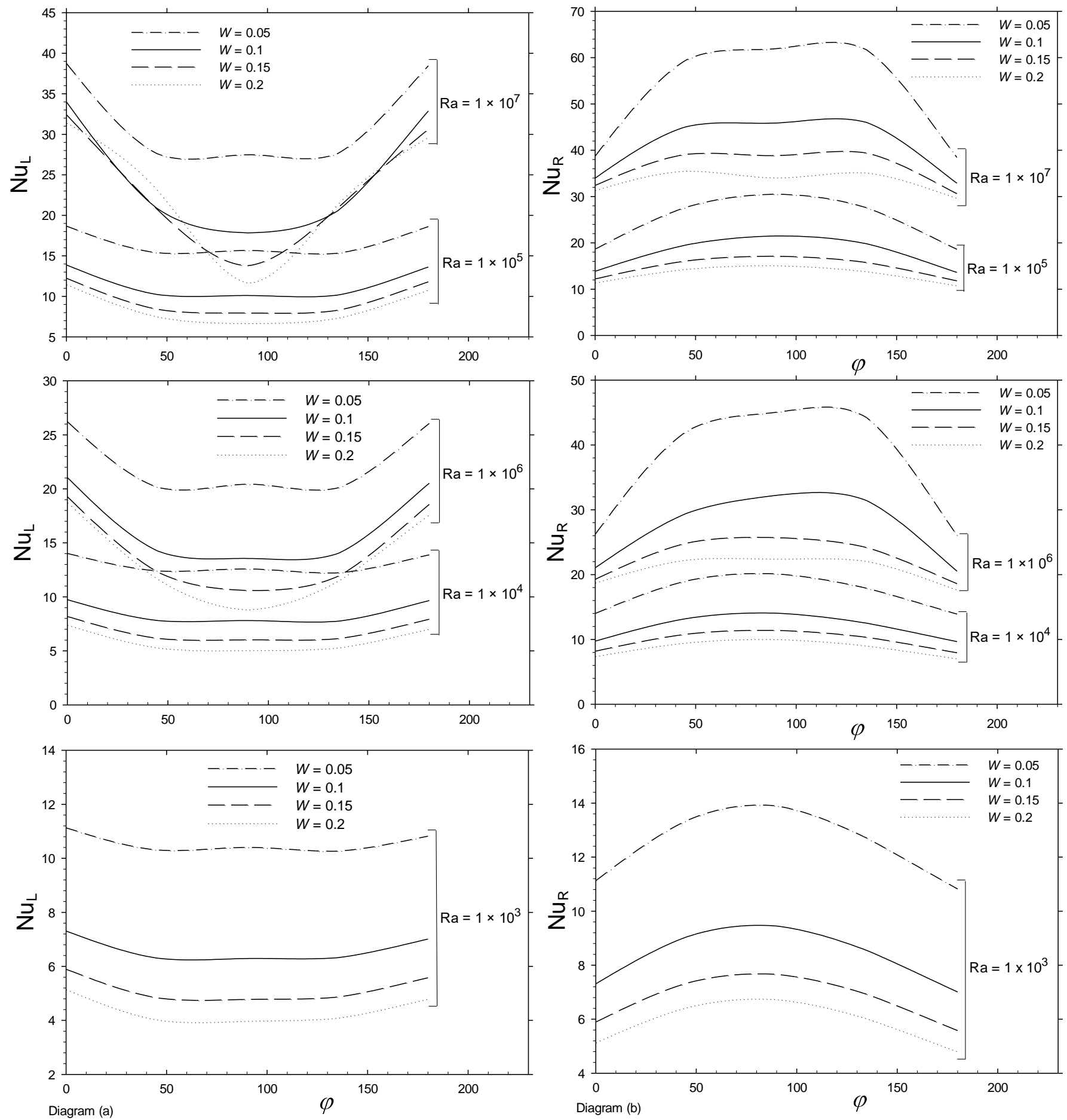

Figure 14. Variations in the mean Nusselt number of a slender cuboid with inclination $\varphi$ for different $R a$ and $W$ for (a) left-side and (b) right-side surfaces. 

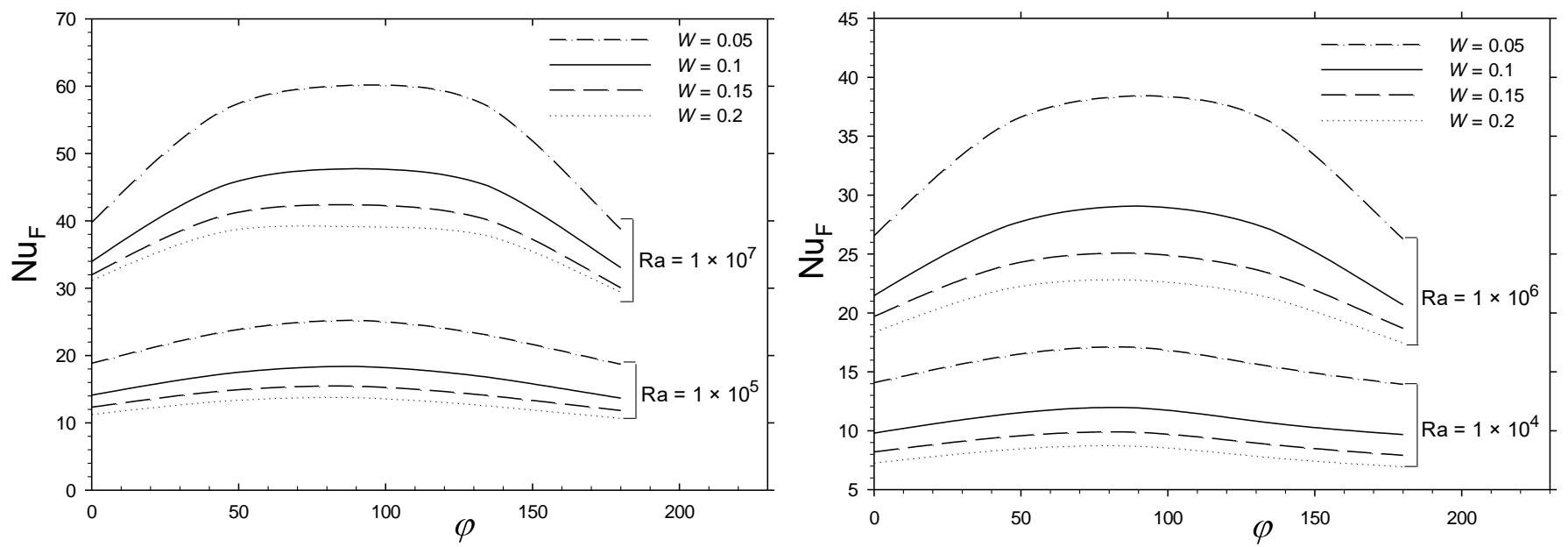

Figure 15. Variations in mean Nusselt number for the front of a slender cuboid with inclination $\varphi$ for different $R a$ and $W$.

Typical variations in $N u_{m}, N u_{F}, N u_{R}$, and $N u_{L}$ with $\varphi$ and $R a=1 \times 10^{4}, 1 \times 10^{6}$ and $W=0.2,0.05$ are presented in Figure 19. The results in this figure show that the mean Nusselt numbers of individual surfaces $\left(N u_{F}, N u_{R}\right.$, and $\left.N u_{L}\right)$ have the same values when $\varphi$ is set to $0^{\circ}$ and $180^{\circ}$ and have approximately the same rate of heat transfer. This figure illustrates that for $W=0.2$, and $R a=1 \times 10^{4}$ and $1 \times 10^{6}$, the value of $N u_{L}$ is less than that of $N u_{F}$ and $\mathrm{Nu}_{\mathrm{R}}$ when $0^{\circ}<\varphi<180^{\circ}$. However, this difference increases as $\varphi$ increases; for $\varphi=90^{\circ}$ it is at a maximum, then it decreases until $\varphi$ is equal to $180^{\circ}$. These variations in the mean Nusselt number arise due to the fact that as the inclination angle of the slender cuboid increases from $0^{\circ}$ to $90^{\circ}$ the left-side surface changes from vertical to horizontally upwards which is an inactive position relative to other surfaces. As $\varphi$ increases from $90^{\circ}$ to $180^{\circ}$ the left-side surface changes from horizontally upwards to vertical again. In fact, $N u_{F}$ and $N u_{R}$ are closer in value when $R a$ is high than when it is low. This figure also illustrates that, for $W=0.05$, and $R a=1 \times 10^{4}$ and $1 \times 10^{6}$, the value of $N u_{L}$ is less than those of $N u_{F}$ and $N u_{R}$ when $0^{\circ}<\varphi<180^{\circ}$. However, as $\varphi$ increases, this change in the mean Nusselt number increases and is at a maximum when $\varphi$ is $90^{\circ}$ and at lower $\operatorname{Ra}$ values; the difference in the mean Nusselt number then decreases until $\varphi$ is $180^{\circ}$. For higher values of $R a$, however, the maximum value of $N u_{R}$ occurs when $\varphi$ is $135^{\circ}$. In fact, for lower $W$ and $R a$ values, the $N u_{m}$ values move closer to $N u_{F}$ where the rate of heat transfer is dominated by the front surface. 


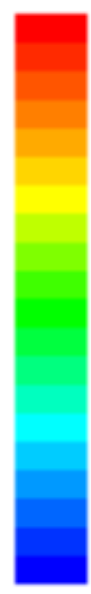

0.172

0.168

0.163

0.158

0.154

0.149

0.145

0.14

0.135

0.131

0.126

0.121

0.117

0.112

0.108

0.103

0.0984

0.0938

0.0992

0.0846

0.08

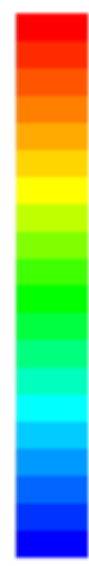

0.196

0.186

0.177

0.167

0.158

0.148

0.139

0.129

0.12

0.1

0.1

0.0909

0.0813

0.0718

0.0623

0.0527

0.0432

0.0336

0.0241

0.0145

Left Side

$\phi=90^{\circ}$

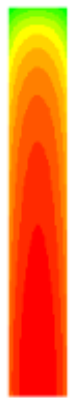

Left Side

$\phi=0^{\circ}$

Right Side

$\boldsymbol{\varphi}=0^{\circ}$

$\boldsymbol{\varphi}=0^{\circ}$

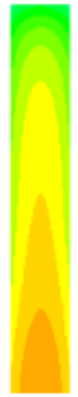

Right Side

$\phi=90^{\circ}$
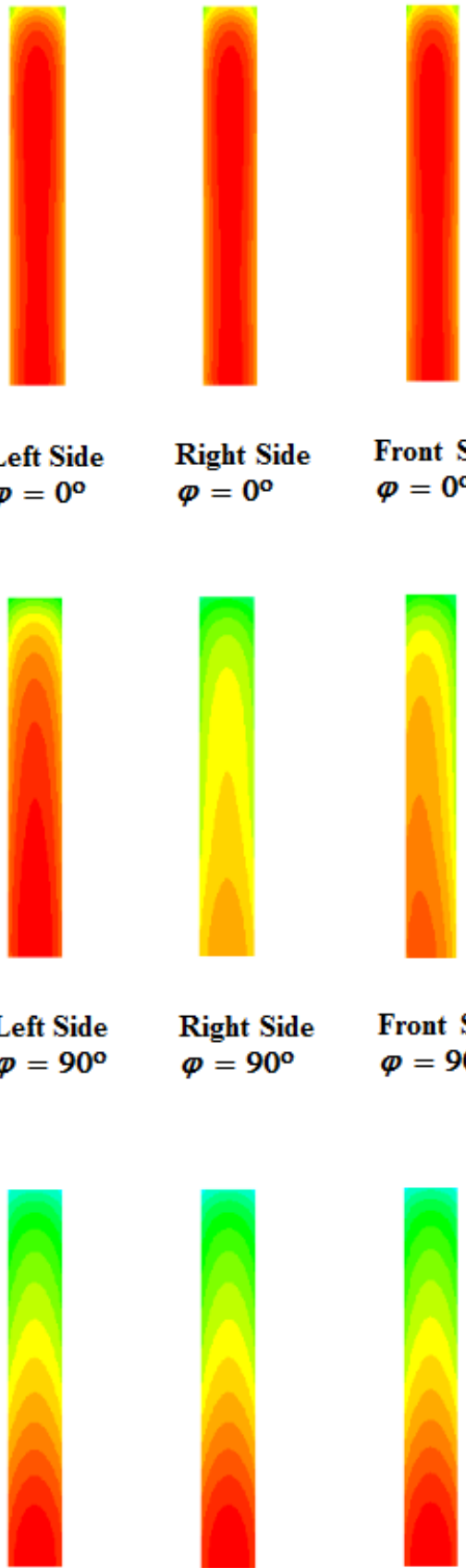

0.229
0.218
0.207
0.196
0.185
0.174
0.163
0.152
0.141
0.131
0.12
0.109
0.0977
0.0867
0.0757
0.0648
0.0538
0.0429
0.0319
0.021
0.01
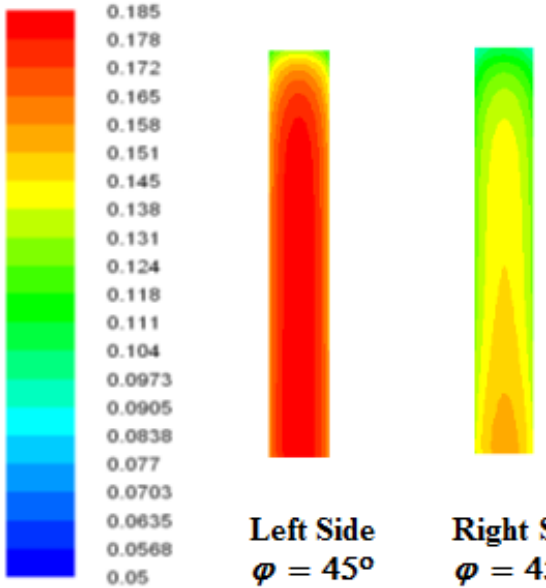

Left Side

Right Side

$\phi=45^{\circ}$

Front Side

$\phi=45^{\circ}$

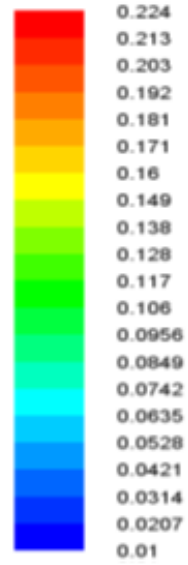

$\phi=90^{\circ}$

Right Side

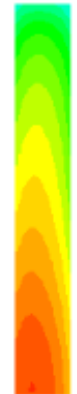

Left Side

$\phi=135^{\circ}$

Right Side

$\phi=135^{\circ}$

Front Side

$\phi=135^{\circ}$
Left Side

$\phi=180^{\circ}$

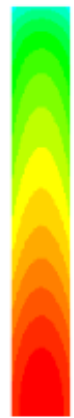

$\phi=180^{\circ}$

Figure 16. Variations in temperature distribution over the left-side, right-side, and front surfaces of the slender cuboid at different positions, $\varphi$, when $R a^{*}=1 \times 10^{4}$ and $W=0.15$. 


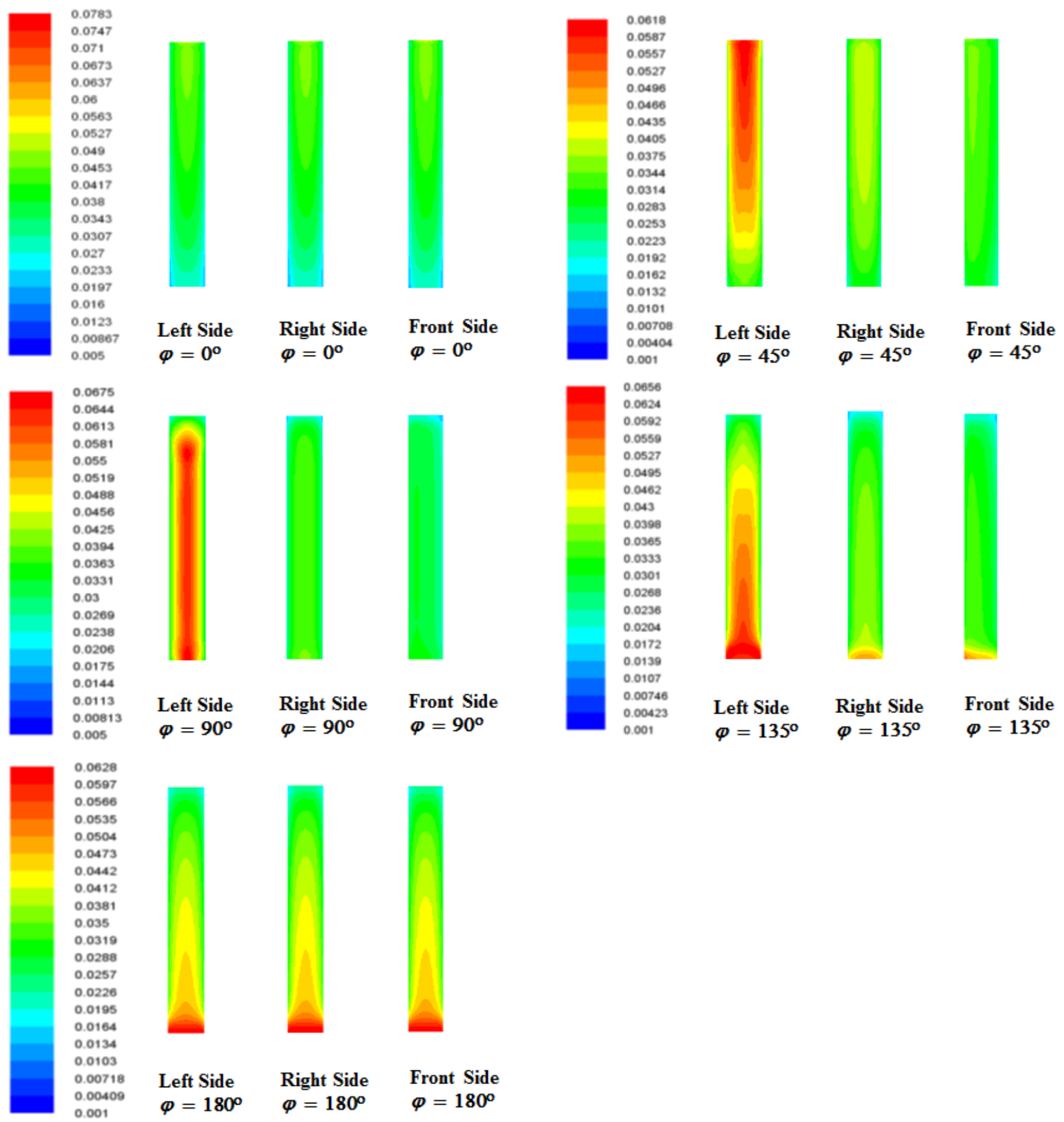

Figure 17. Variations in temperature distribution over the left-side, right-side, and front surfaces of the slender cuboid at different positions, $\varphi$, when $R a^{*}=1 \times 10^{8}$ and $W=0.15$. 


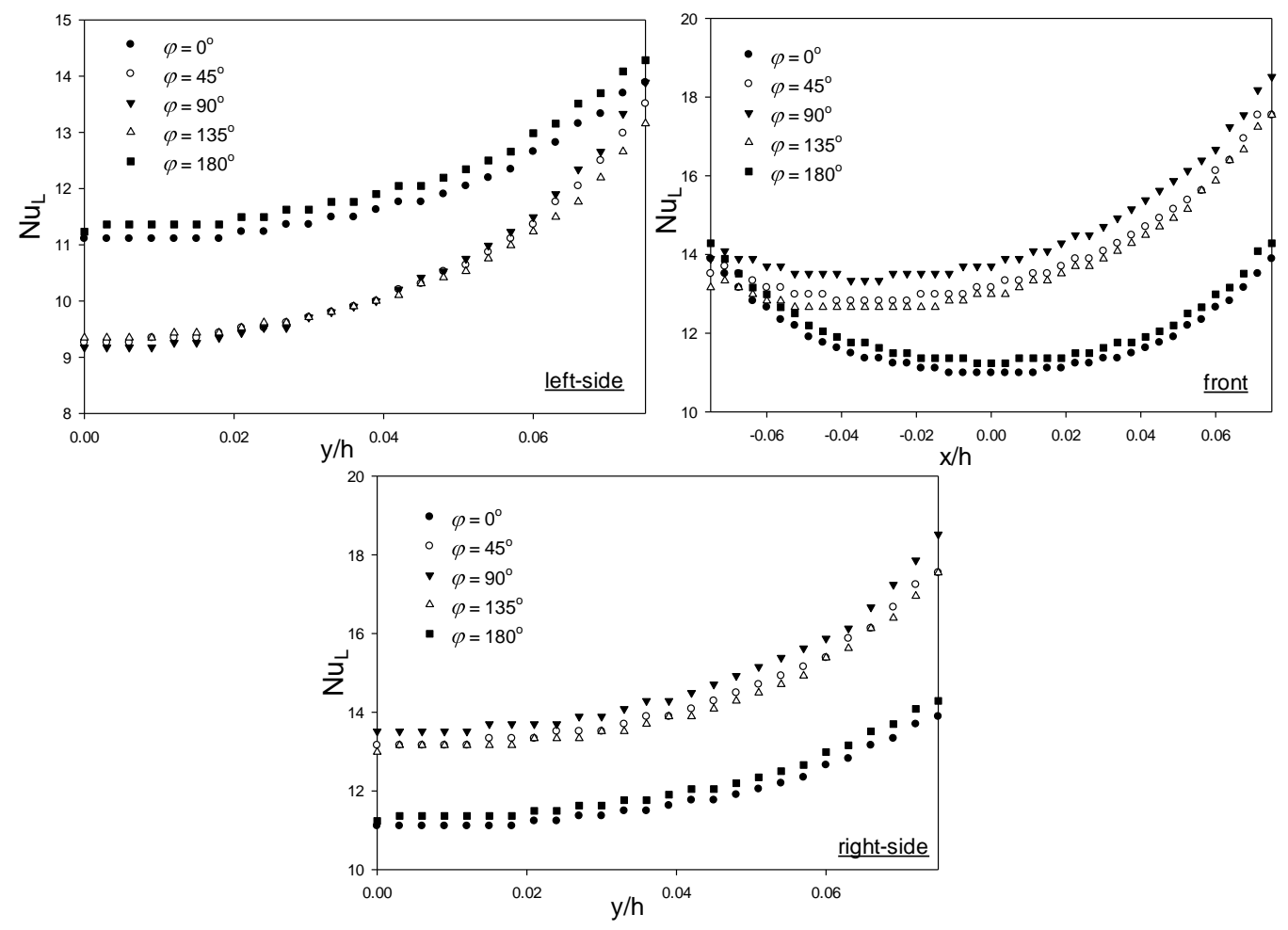

Figure 18. Variations in local Nusselt number over the left-side, front, and right-side surfaces respectively of the slender cuboid with dimensionless distance along the horizontal center-line $(\mathrm{z} / \mathrm{h}=0.5)$ at different positions when $R a^{*}=1 \times 10^{6}$ and $W=0.15$.
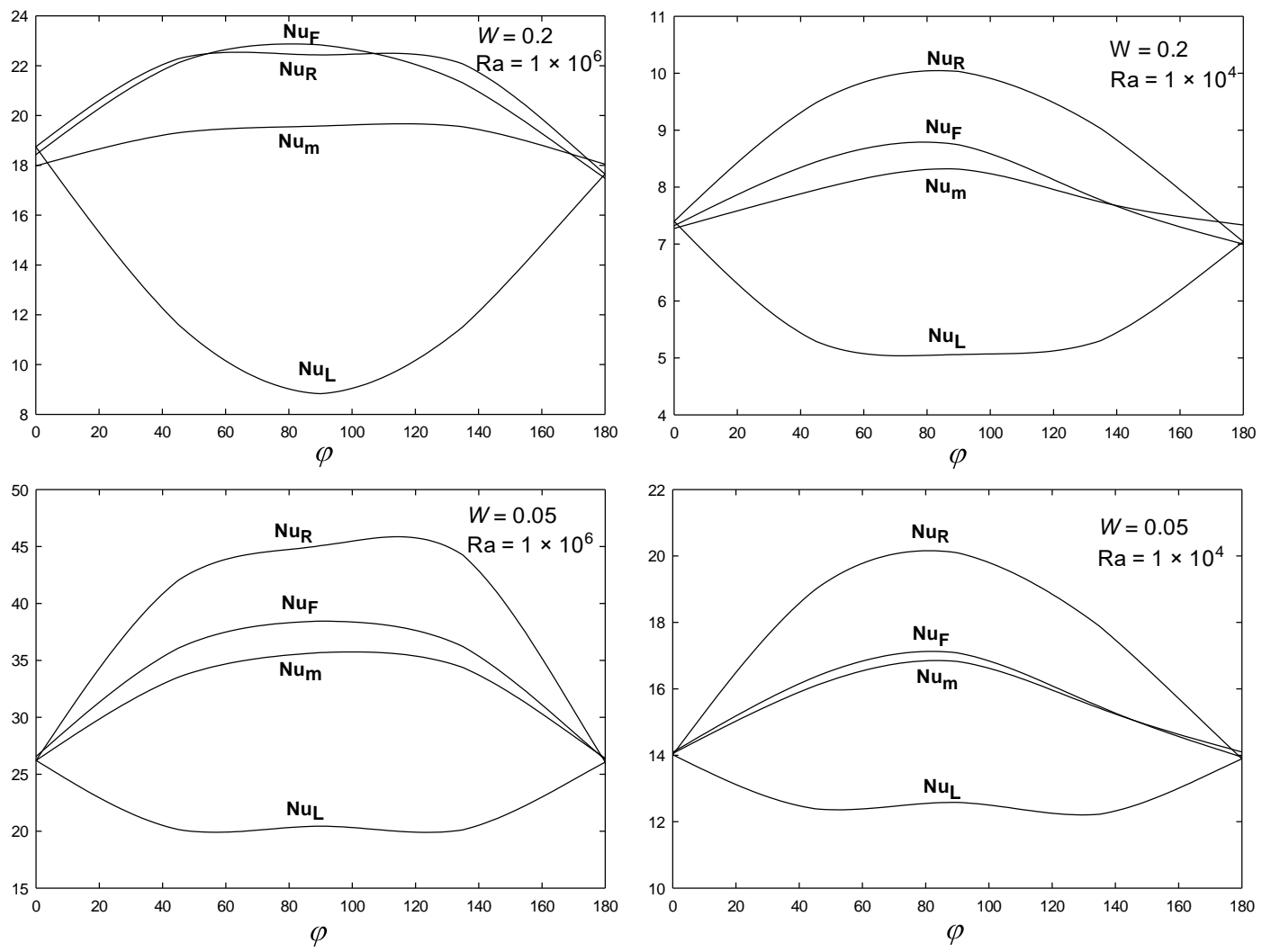

Figure 19. Variations in the mean, front, right-side, and left-side surface Nusselt numbers for a slender cuboid at inclinations $\varphi$ for Rayleigh numbers of $R a=1 \times 10^{4}$ and $R a=1 \times 10^{6}$, and for $W=0.2$ and $W=0.05$. 


\subsection{Correlating the Numerical Results}

The surfaces of the slender cuboid are connected flat plates. The procedures described in Kalendar and Oosthouizen [29] are adopted to correlate the obtained results. In the case of a wide, flat plate with a constant surface temperature, the correlation equation is described as

$$
N u_{0}=B R a^{0.25}
$$

The parameter $B$ is dependent only on the Prandtl number of the fluid involved. Furthermore, as the width of the slender cuboid reduces and the cuboid is placed at an inclined angle relative to the vertical, edge effects become significant (see Kalendar and Oosthuizen [29]) and the Nusselt number is dependent on the ratio of the thickness of the boundary layer to the cuboid width (this is because the thickness of the boundary layer is being dependent on the value defined in Equation (15))

$$
\varepsilon=\frac{h}{w R a^{0.25}}=\frac{1}{W R a^{0.25}}
$$

heat transfer from the slender cuboid is described by the equation

$$
\frac{N u}{R a^{0.25}}=\text { constant }+ \text { function }(R a, W, \varphi)
$$

The current numerical simulation of the mean Nusselt number for the case of an isothermally heated slender cuboid and an exposed top surface pointing between vertically upward and vertically downward ( $\varphi$ from $0^{\circ}$ to $180^{\circ}$ ) with dimensionless widths, $W$, of $0.2-0.05$ and Rayleigh number, $R a$, between $10^{3}$ and $10^{7}$ can be approximately described in the form of Equation (16) by the equation

$$
\frac{N u_{e m p}}{R a^{n}}=A+\frac{B}{\left(W R a^{0.25}\right)^{0.95}}
$$

In general, the constants $A, B$, and $n$ in Equation (17) depend on the inclination angle $\varphi$ and cannot be correlated in a simple form. However, for simplification it is assumed that the constants are not dependent on $\varphi$ and Equation (17) was fitted to all the numerical simulation outcomes for all considered values of $\varphi$ in this study. Table 3 summarizes the values obtained for each constant. The results from Equation (17), using these values for the constants, were compared with the numerical results and are presented in Figure 19. The percentage difference between the results given by Equation (17) and the numerical results, and for all Rayleigh numbers, lies between $19.46 \%$ and $0.08 \%$. The differences between the numerical results and the results given by Equation (17) indicate that the values of constants should be taken as a function of $\varphi$ for better accuracy. This is to be expected because the nature of the flow over the slender cuboid for $\varphi$ near $0^{\circ}$ will be different from that for $\varphi$ near $180^{\circ}$ and both of these flows will differ from the flow that exists at angles between $0^{\circ}$ and $180^{\circ}$. No simple expression with better accuracy can be determined for the variation in the values of the constants with $\varphi$.

Table 3. Values of constants $n, A$, and $B$ used in Equation (17).

\begin{tabular}{cccc}
\hline Angle, $\boldsymbol{\varphi}$ & Value of $\boldsymbol{n}$ & Best Fit Value of $\boldsymbol{A}$ & Best Fit Value of $\boldsymbol{B}$ \\
\hline $0^{\circ}, 45^{\circ}, 90^{\circ}, 135^{\circ}$ and $180^{\circ}$ & 0.28 & 0.3 & 0.5 \\
$0^{\circ}$ & 0.25 & 0.47 & 0.5 \\
$180^{\circ}$ & 0.25 & 0.47 & 0.52 \\
$45^{\circ}$ & 0.28 & 0.3 & 0.58 \\
$90^{\circ}$ & 0.28 & 0.3 & 0.6 \\
$135^{\circ}$ & 0.28 & 0.3 & 0.55 \\
\hline
\end{tabular}


Therefore, several simple correlations in the form of Equation (17), with different constant values for different inclination angles, $\varphi$, were derived and are given in Table 3 . The derived values of the constants for different angles allow for more accurate estimates of the mean Nusselt number for different inclination angles, $\varphi$. Therefore, the values of the constants that provide the best fit to the results for angles $\varphi=0^{\circ}, 180^{\circ}, 45^{\circ}, 90^{\circ}$, and $135^{\circ}$ are given in Table 3. Figure 20 shows comparisons of the results produced using Equation (17) and given in Table 3, for these different values of the constants for the specified angles, with all numerical simulation results produced in this current study. Furthermore, for the case when $\varphi=0^{\circ}$ and $180^{\circ}$, Figure 20 shows that the percentage difference between the results given by Equation (17) and the numerical results lies between $5.7 \%$ and $0.03 \%$. While for the case when $\varphi=45^{\circ}, 90^{\circ}$, and $135^{\circ}$ Figure 20 shows that the percentage difference between the results given by Equation (17) and the numerical results lies between $9.25 \%$ and $0.05 \%$. From these results, it is concluded that sound agreement exists between the obtained correlation equations and present numerical results.

The denominator on the left-hand side of Equation (17) for inclination angles of $\varphi=45^{\circ}, 90^{\circ}$, and $135^{\circ}$ exhibits a Rayleigh number raised to the power 0.28 instead of 0.25 , since the flow interaction phenomena over the surfaces of the slender cuboid become more significant as $\varphi$ and $W$ change. This equation has the same form as derived previously by Kalendar and Oosthuizen [29] and is applied for dimensionless widths in the range $0.25 \leq W \leq 1$ to an inclined slender cuboid with an exposed top surface.

Figure 21 shows the numerical results and the mean Nusselt number correlation equations obtained for a slender cuboid subjected to heat flux Rayleigh numbers between $10^{3}$ and $10^{9}$, and with dimensionless widths of $0.25-0.05$ and inclination angles of $0^{\circ}, 45^{\circ}$, $90^{\circ}, 135^{\circ}$, and $180^{\circ}$. The parameters which influence the mean Nusselt number are the heat flux Rayleigh number, width of the slender cuboid, and the inclination angle. Therefore, the rate of heat transfer from the slender cuboid can be adequately described by the equation

$$
\frac{N u}{R a^{* 0.2}}=\text { constant }+\operatorname{function}\left(R a^{*}, W, \varphi\right)
$$

However, for an inclined slender cuboid exhibiting surface heat flux which is uniform, the numerical results can be fitted approximately using the equation

$$
\frac{N u}{R a^{*(0.2+B \sin \varphi)}}=A\left(\frac{1}{W R a^{*(0.2+B \sin \varphi)}}\right)+C
$$

where $A, B$, and $C$ are constants; the forms of the correlation equations are listed in Table 4 .

Table 4. Forms and values of constants used in Equation (19).

\begin{tabular}{ccc}
\hline Angle,$\varphi$ & Remarks & Best Fit Equation \\
\hline $0^{\circ}, 180^{\circ}$ & & $\frac{N u}{R a^{*(0.2)}}=0.36\left(\frac{1}{W R a^{*}(0.2)}\right)+0.6$ \\
$45^{\circ}$ & & $\frac{N u}{R a^{*}(0.2+0.05 \sin \varphi)}=-0.053\left(\frac{N u}{W R a^{*}(0.2+0.05 \sin \varphi)}\right)^{2}+0.6\left(\frac{1}{W R a^{*}(0.2+0.05 \sin \varphi)}\right)+0.33$ \\
$135^{\circ}$ & $\frac{1}{R a^{*(0.2+0.05 \sin \varphi)}}=-0.05\left(\frac{1}{W R a^{*(0.2+0.05 \sin \varphi)}}\right)^{2}+0.57\left(\frac{1}{W R a^{*}(0.2+0.05 \sin \varphi)}\right)+0.33$ \\
$90^{\circ}$ & $\left(\frac{1}{W R a^{* 0.2}}\right)<1.1$ & $\frac{N u}{R q^{*(0.2)}}=0.9\left(\frac{1}{W R a^{*(0.2)}}\right)+0.19$ \\
& $\left(\frac{1}{W R a^{* 0.2}}\right)>1.1$ & $\frac{N u}{R a^{*(0.2)}}=0.35\left(\frac{1}{W R a^{*}(0.2)}\right)+0.49$ \\
\hline
\end{tabular}



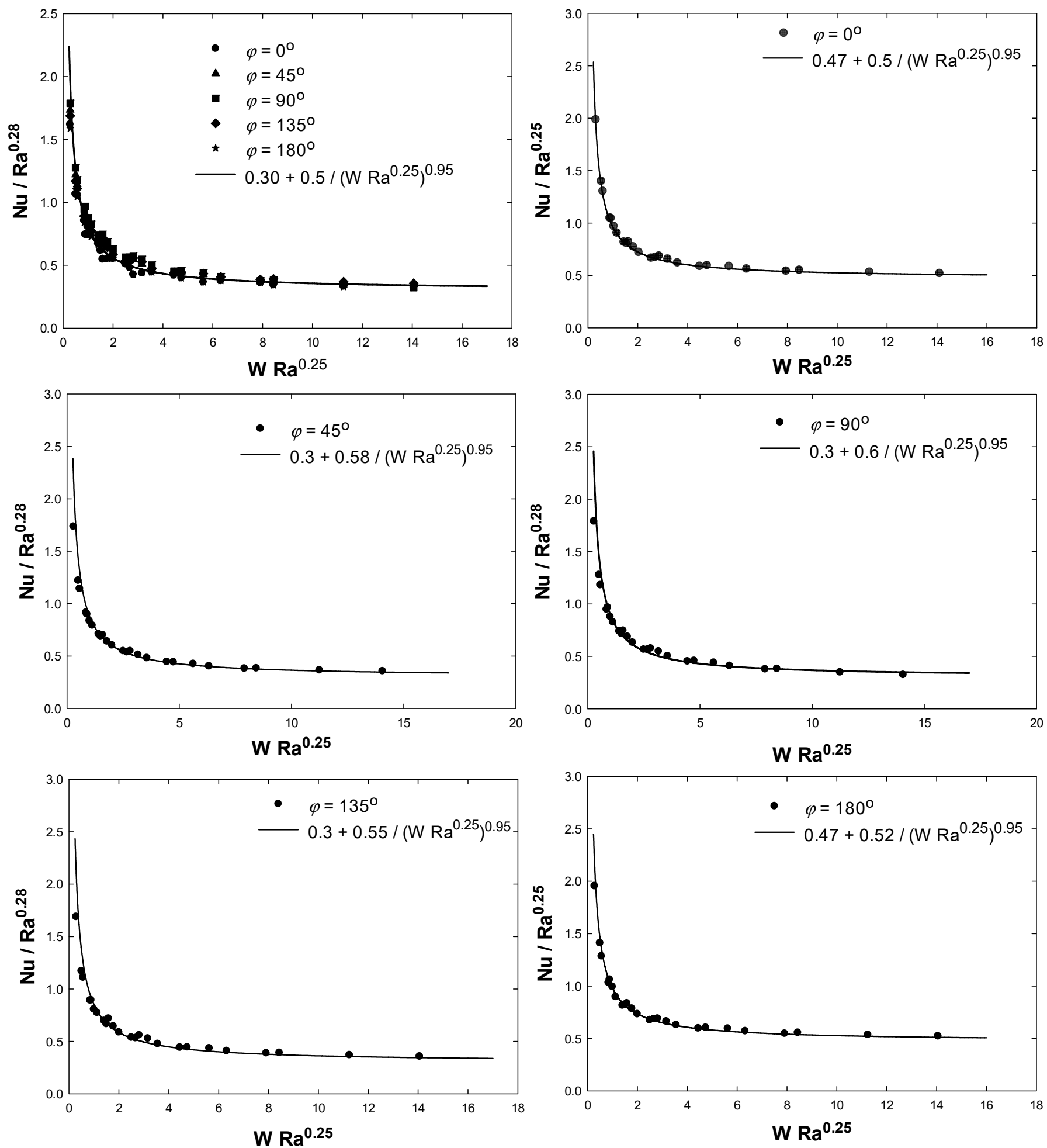

Figure 20. Comparison between present correlation equation and numerical results for different inclination angles $\varphi=0^{\circ}$, $45^{\circ}, 90^{\circ}, 135^{\circ}$, and $180^{\circ}$. 

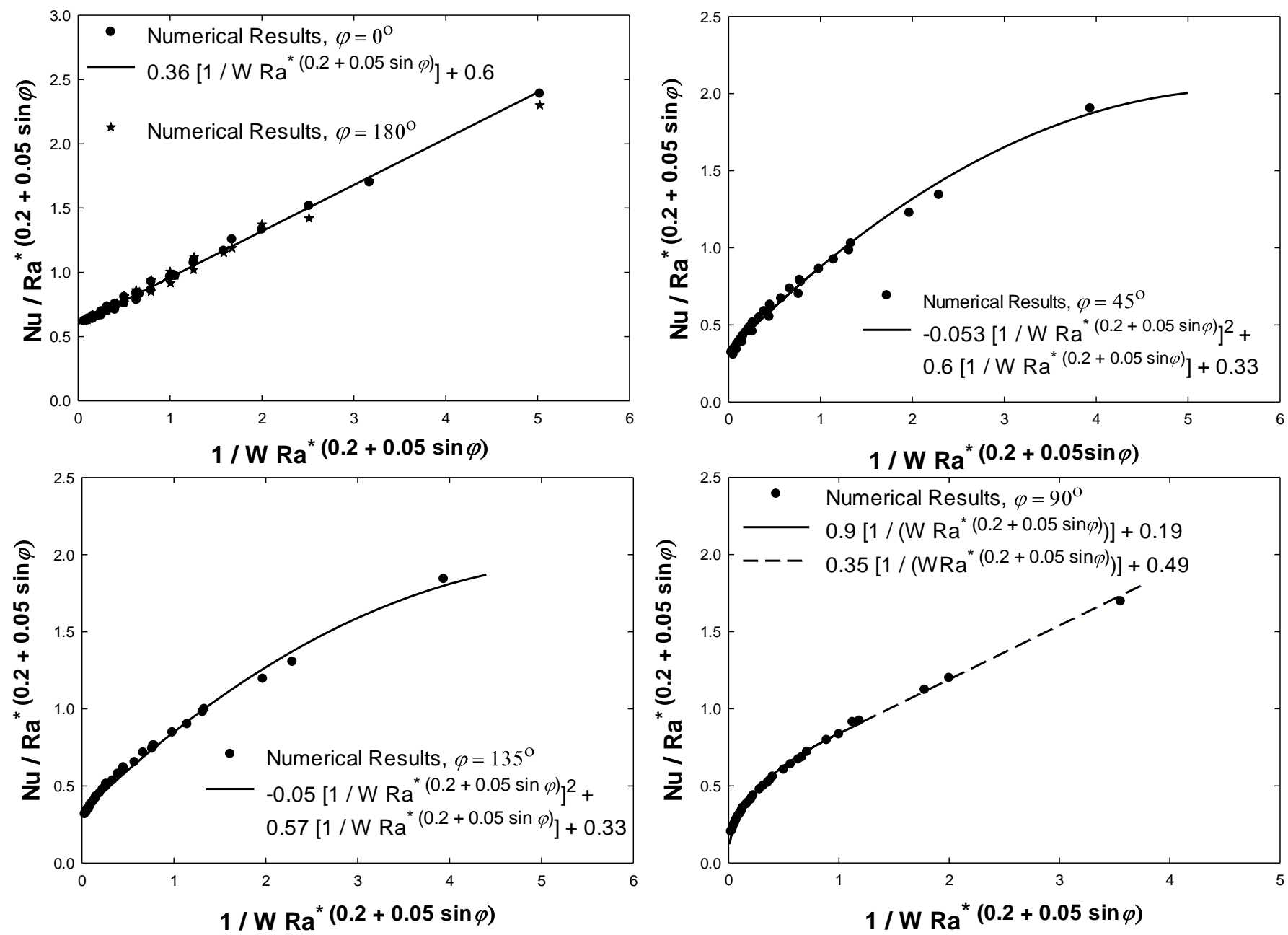

Figure 21. Comparison between present correlation equation and numerical results for different inclination angles, heat flux Rayleigh numbers, and dimensionless widths used in the present study.

The derived forms of the equation and values of the constants for the different angles allow more accurate estimates of the mean Nusselt number to be calculated for each inclination angle, $\varphi$. Results given by Equation (19) are shown in Table 4 and are compared with the present results for heat transfer of the slender cuboid in Figure 21. The correlation equation line in these figures represents the best fit for the present numerical results. The percentage difference between the best fit for the numerical simulation results and the results obtained through the correlation equations is shown in Figure 21 for the cases of $\varphi=0^{\circ}$ and $180^{\circ}, \varphi=45^{\circ}, \varphi=135^{\circ}$, and $\varphi=90^{\circ}$, and falls within the ranges $5.76-0.06 \%$, $7.3-0.23 \%, 8.62-0.23 \%$, and $8-0.35 \%$, respectively. As previously discussed, the correlation equations developed are useful for modeling natural convective heat transfer in many engineering applications.

Figure 22 shows the comparison between the present correlation Equation (17) with referenced studies to show the general relation trends of Equation (17) with other correlations available in the literature. The comparison between the present correlation Equation (17) with correlations is available in the literature for the cases of laminar natural convective flow in air over vertical square and circular cylinders with constant wall temperature boundary conditions. The present correlation equations, as general relation trends, exhibited good agreement with available related correlation equations found in the literature. 


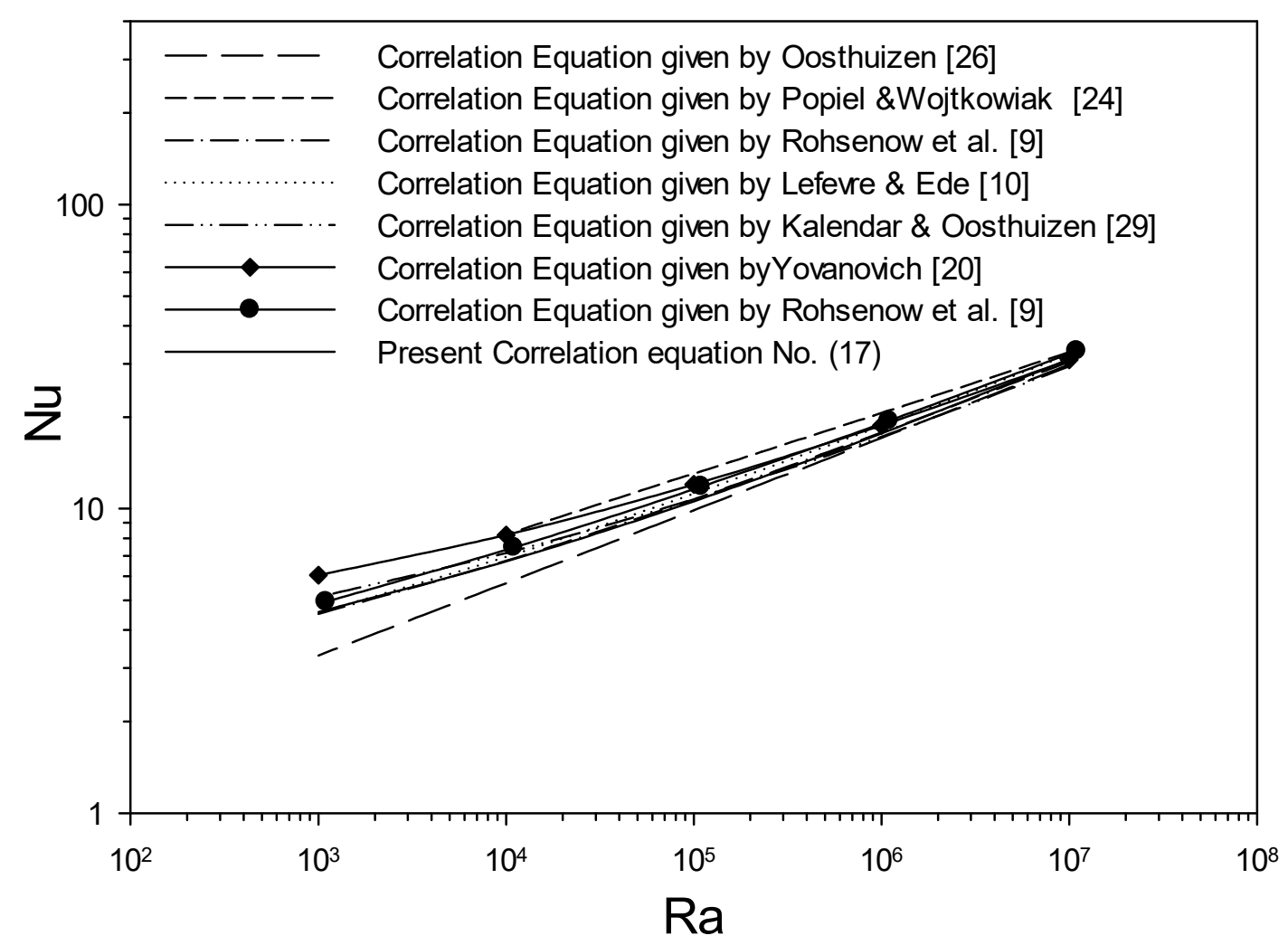

Figure 22. Comparison between present correlation Equation (17) and correlation equations available in the literature for inclination angle $\varphi=0^{\circ}$ and $W=0.25$.

\section{Conclusions}

In this study, the natural laminar convective heat transfer from a cuboid with a narrow cross-section (square) and an exposed top surface, with two imposed boundary conditions of constant temperature and constant heat flux, was investigated. The main conclusions drawn from the results are listed below:

- The values of the mean Nusselt number for the total heated surface of the cuboid and for the separate heated surfaces decreased with increasing dimensionless width under all considered conditions.

- The values of the mean Nusselt number for the heated surfaces as a whole and for the individual heated surfaces of the slender cuboid change with position, dimensionless width, heat flux Rayleigh number, and Rayleigh number due to edge effects as well as the interaction of the buoyancy-driven natural flow over the surfaces that make up the cuboid.

- The mean Nusselt numbers obtained for the heated surfaces of the slender cuboid are almost independent of position at the lowest value of the heat flux Rayleigh number and Rayleigh number, for all dimensionless widths considered. However, at a high heat flux Rayleigh number and Rayleigh number, the mean Nusselt number behaves differently for higher $W$ values than for lower $W$ values.

- The mean Nusselt number for individual surfaces of the slender cuboid changes in magnitude with the inclination angle, $\varphi$, and is different at lower and higher Rayleigh numbers and heat flux Rayleigh numbers. The maximum and minimum magnitude of the mean Nusselt number for individual surfaces of the slender cuboid changes as the angles of inclination change between $0^{\circ}$ and $180^{\circ}$. The maximum and minimum magnitude of the mean Nusselt number for individual surfaces of the slender cuboid at different inclination angles change with the values of Rayleigh numbers and heat flux Rayleigh numbers. 
- The mean Nusselt number values from the individual heated surfaces of the slender cuboid are less significant and there are small changes in the mean Nusselt number at the lowest values of the Rayleigh number and heat flux Rayleigh number and for higher, $W$, dimensionless width, greater than 0.15 for all values of inclination angle, $\varphi$.

- The obtained mean Nusselt number for slender cuboids for the case of constant temperature boundary conditions with different angles of inclination, a broad range of Rayleigh numbers, and different dimensionless widths can be adequately derived from Equation (17).

- The mean Nusselt number for a slender cuboid under constant heat flux boundary conditions, at different angles of inclination, with a broad range of heat flux Rayleigh numbers, and different dimensionless widths can be adequately derived from Equation (19).

- Natural convective heat transfer from a cuboid cylinder in transition and a turbulent flow region needs to be investigated as future research. Transient natural convective flow over an inclined slender cuboid is a subject of interest for future investigation.

Author Contributions: Conceptualization, A.K and P.O.; methodology, A.K. and S.H.; Softwar modeling, A.K. and Y.A; Validation; A.K. and Y.A.; Formal analysis; A.K., Y.A. and S.H.; Investigation, A.K., S.H. and P.O.; Resourses, A.K. and Y.A.; Data curation A.K. and Y.A.; Plotting, A.K and Y.A.; Writing-original draft preparation, A.K. and Y.A.; Writing-review and editing, S.H. and P.O.; Project administration, A.K and Y.A. All authors have read and agreed to the published version of the manuscript.

Funding: This research received no external funding.

Institutional Review Board Statement: Not related, this study did not involve humans or animals.

Informed Consent Statement: Not related.

Data Availability Statement: Not related.

Acknowledgments: This work was supported by the Public Authority for Applied Education and Training of Kuwait (PAAET).

Conflicts of Interest: The authors declare no conflict of interest.

\section{Nomenclature}

$\begin{array}{ll}A, B & \text { Best fit value for constants given in Table } 3 \text { which are used in Equation (17) } \\ g & \text { Gravitational acceleration, } \mathrm{m} \cdot \mathrm{s}^{-2} \\ h & \text { Height of heated slender cuboid, } \mathrm{m} \\ k & \text { Thermal conductivity of fluid, } \mathrm{W} \cdot \mathrm{m}^{-1} \cdot \mathrm{K}^{-1} \\ N u & \text { Numerical mean Nusselt number based on } \mathrm{h} \text { and } q_{w}^{\prime} h / k \\ N u_{w} & \text { Mean Nusselt number based on } \mathrm{w} \text { and } q_{w}^{\prime} w / k \\ N u_{l e f t} & \text { Numerical mean Nusselt number for heated left-side surface of slender cuboid } \\ N u_{r i g h t} & \text { Numerical mean Nusselt number for heated right-side surface of slender cuboid } \\ N u_{f r o n t} & \text { Numerical mean Nusselt number for heated front surface of slender cuboid } \\ n & \text { Value of constant given in Table } 3 \text { which is used in Equation }(17) \\ N u & \text { Numerical and experimental mean Nusselt number based on } h \\ N u_{e m p} & \text { Empirical mean Nusselt number for the entire heated surface of the slender cuboid } \\ N u_{m} & \text { Mean Nusselt number based on h and on }\left(T_{w}-T_{F}\right) \\ N u_{L} & \text { Mean Nusselt number for heated left-side surface of slender cuboid } \\ N u_{R} & \text { Mean Nusselt number for heated right-side surface of slender cuboid } \\ N u_{F} & \text { Mean Nusselt number for heated front surface of slender cuboid } \\ P r & \text { Prandtl number } \\ P & \text { Dimensionless pressure } \\ p & \text { Pressure, Pa }\end{array}$




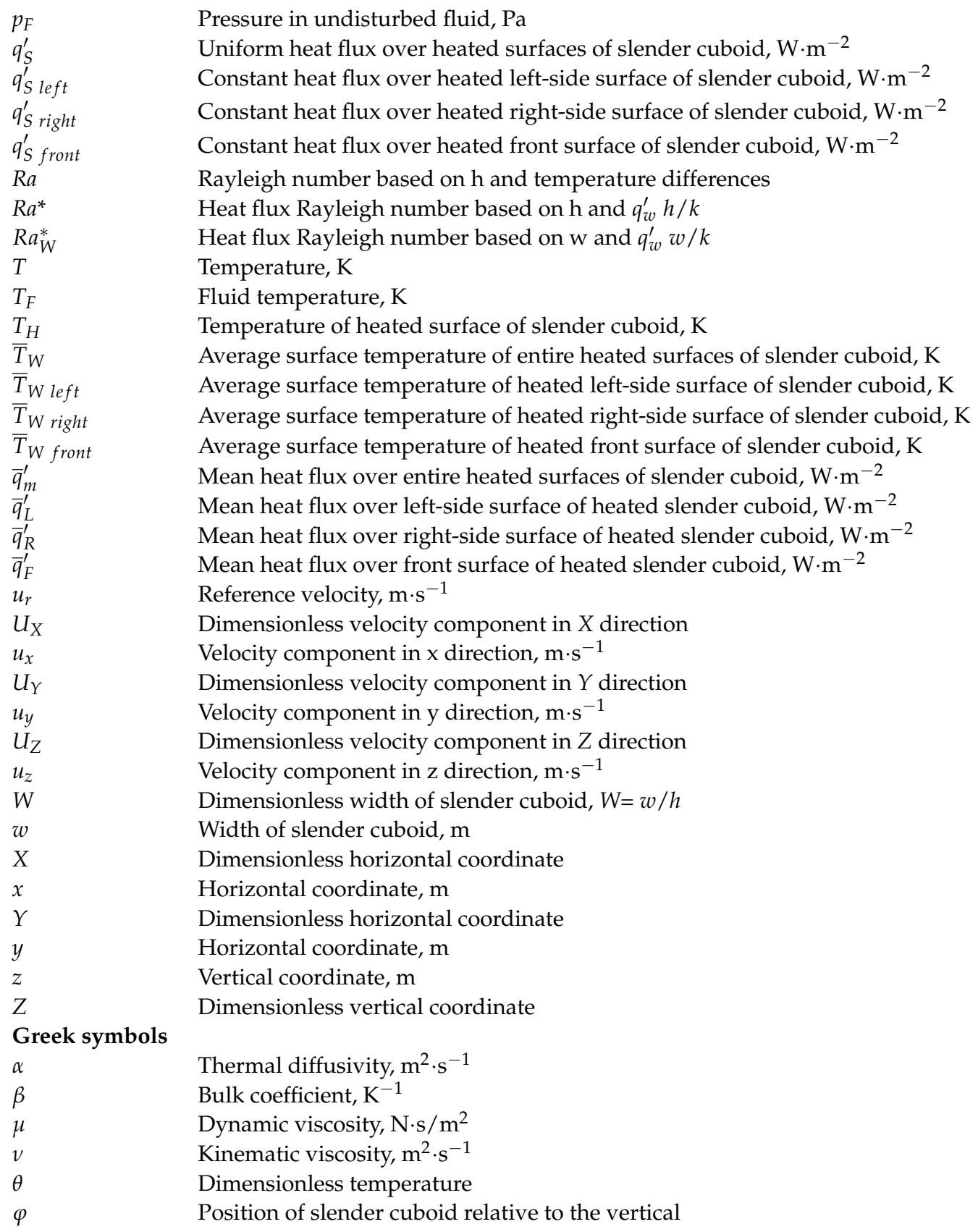

\section{References}

1. Incropera, F. Convection heat transfer in electronic equipment cooling. J. Heat Transfer. 1988, 110, 1097-1111. [CrossRef]

2. Honnor, F.; Thomas, M.A. Packaging and cooling problems associated with microelectronics equipment. Microelectron. Reliab. 1969, 8, 331-338. [CrossRef]

3. Yeh, L.T. Review of heat transfer technologies in electronic equipment. ASME J. Electron. Package. 1995, 117, 333-339. [CrossRef]

4. Dave, S.S. Cooling Techniques for Electronic Equipment, 2nd ed.; John Wiley \& Sons: New York, NY, USA, 1991.

5. Incropera, F.; Dewitt, D.; Bergman, T.; Lavine, A. Fundamentals of Heat and Mass Transfer, 6th ed.; John Wiley: New York, NY, USA, 2005.

6. $\quad$ Burmeister, L. Convective Heat Transfer, 2nd ed.; John Wiley: New York, NY, USA, 1993.

7. Oleg, G.; Pavel, P. Free-Convective Heat Transfer, 1st ed.; Springer: Berlin/Heidelberg, Germany, 2005.

8. Cebeci, T. Laminar-free-convective-heat transfer from the outer surface of vertical slender circular cylinder. In Proceedings of the 5th International Heat Transfer Conference, Tokyo, Japan, 3-7 September 1974; p. 15.

9. Rohsenow, W.; Hartnett, J.; Cho, Y. Hand Book of Heat Transfer; McGraw-Hill: New York, NY, USA, 1998.

10. Le Fevre, E.J.; Ede, A. Laminar free convection from the outer surface of a vertical circular cylinder. In Proceedings of the 9th International Congress on Applied Mechanics, Brussels, Belgium, 5-13 September 1956; pp. 175-183.

11. Crane, L. Natural convection from a vertical cylinder at very large Prandtl numbers. J. Eng. Math. 1976, 10, 115-124. [CrossRef] 
12. Oosthuizen, P. Free convective heat transfer from vertical cylinders with exposed ends. Trans. Can. Soc. Mech. Eng. 1979, 5, 231-234. [CrossRef]

13. Oosthuizen, P.; Paul, J. Free convective heat transfer from short horizontal cylinders. In CANCAM 81: 8th Congress Canadien de Mecanique Appliquee; University of Moncton, Faculty of Science \& Engineering: Moncton, NB, Canada, $1981 ;$ p. 711.

14. Oosthuizen, P. Natural convective heat transfer from a vertical cylinder with an exposed upper surface. In Proceedings of the ASME/JSME Thermal Engineering Summer Heat Transfer Conference, Vancouver, BC, Canada, 8-12 July 2007; pp. 489-495. [CrossRef]

15. Oosthuizen, P.; Paul, J. Natural convective heat transfer from an isothermal cylinder with an exposed upper surface mounted on a flat adiabatic base with a flat adiabatic surface above the cylinder. In Proceedings of the EUROTHERM 5th European Thermal Science Conference, Eindhoven, The Netherlands, 18-22 May 2008.

16. Eslami, M.; Jafarpur, K. Laminar natural convection heat transfer from isothermal cylinders with active ends. Int. J. Heat Transf. Eng. 2011, 32, 506-513. [CrossRef]

17. Popiel, C. Free convection heat transfer from vertical slender cylinders: A review. Int. J. Heat Transf. Eng. 2008, 29, 521-536. [CrossRef]

18. Popiel, C.; Wojtkowiak, J.; Bober, K. Laminar free convective heat transfer from isothermal vertical slender cylinder. Exp. Therm. Fluid Sci. 2007, 32, 607-613. [CrossRef]

19. Lee, S.; Yovanovich, M.; Jafarpur, K. Effects of geometry and orientation on laminar natural convection from isothermal bodies. $J$. Thermophys. Heat Transf. 1991, 5, 208-216. [CrossRef]

20. Yovanovich, M. On the effect of shape, aspect ratio and orientation upon natural convection from isothermal bodies of complex shape. In Proceedings of the ASME National Heat Transfer Conference, Pittsburg, PA, USA, 8-12 August 1987.

21. Radziemska, E.; Lewandowski, W. Natural convective heat transfer from isothermal cuboids. Int. J. Heat Mass Transf. 2003, 46, 2169-2178. [CrossRef]

22. Hassani, A. Natural convection heat transfer from cylinders of arbitrary cross section. J. ASME 1992, 114, 768-777. [CrossRef]

23. Mahmud, S.; Kumar, P.; Hyder, N. Laminar natural convection around an isothermal square cylinder around different orientations. Int. Commun. Heat Mass Transf. 2002, 29, 993-1003. [CrossRef]

24. Popiel, C.; Wojtkowiak, J. Experiments on free convective heat transfer from side walls of a vertical square cylinder in air. Exp. Therm. Fluid Sci. 2004, 29, 1-8. [CrossRef]

25. Al-Arabi, M.; Sarhan, A. Natural convection heat transfer from square cylinders. Appl. Sci. Res. 1984, 41, 93-104. [CrossRef]

26. Oosthuizen, P. Natural convective heat transfer from an isothermal vertical square cylinder mounted on a flat adiabatic base. In Proceedings of the ASME Summer Heat Transfer Conference, ASME, Jacksonville, FL, USA, 10-14 August 2008; pp. 499-505. [CrossRef]

27. Oosthuizen, P. Natural convective heat transfer from a short isothermal square cylinder mounted on a flat adiabatic base. In Proceedings of the 21st Annual Conference of the CFD Society of Canada, Sherbrooke, QC, Canada, 6-9 May 2013.

28. Kalendar, A.; Oosthuizen, P. Natural convective heat transfer from an inclined square cylinder with a uniform surface heat flux and an exposed top surface mounted on a flat adiabatic base. In Proceedings of the 20th International Symposium on Transport Phenomena, Victoria, BC, Canada, 7-10 July 2009.

29. Kalendar, A.; Oosthuizen, P. Numerical and experimental study of natural convective heat transfer from an inclined isothermal square cylinder with an exposed top surface. J. Heat Mass Transf. 2013, 49, 601-616. [CrossRef]

30. Ali, M. Experimental free convection heat transfer from inclined square cylinders. Heat Mass Transf. 2017, 53, 1643-1655. [CrossRef]

31. Huang, R.-T.; Sheu, W.-J.; Wang, C.-C. Orientation effect on natural convective performance of square pin fin heat sinks. Int. J. Heat Mass Transf. 2008, 51, 2368-2376. [CrossRef]

32. Huang, R.-T.; Sheu, W.-J.; Li, H.-Y.; Wang, C.-C.; Yang, K.-S. Natural convection heat transfer from square pin fin heat sinks subject to the influence of orientation. In Proceedings of the Twenty-Second Annual IEEE Semiconductor Thermal Measurement and Management Symposium, Dallas, TX, USA, 14-16 March 2009. [CrossRef]

33. Oosthuizen, P.; Kalendar, A. Natural Convective Heat Transfer from Short Inclined Cylinder; Springer Briefs in Applied Science and Technology, Thermal Engineering and Applied Science; Springer: New York, NY, USA, 2014.

34. Boetcher, S. Natural Convection from Circular Cylinder; Springer Briefs in Applied Science and Technology, Thermal Engineering and Applied Science; Springer: New York, NY, USA, 2014. 